University of Rhode Island

DigitalCommons@URI

Open Access Master's Theses

2015

\title{
A Cross-Sectional Analysis of Bronchodilator Prescribing in COPD and Cardiovascular Comorbidity
}

Damilola Tejumola Adesanoye

University of Rhode Island, dadesanoye@gmail.com

Follow this and additional works at: https://digitalcommons.uri.edu/theses

\section{Recommended Citation}

Adesanoye, Damilola Tejumola, "A Cross-Sectional Analysis of Bronchodilator Prescribing in COPD and Cardiovascular Comorbidity" (2015). Open Access Master's Theses. Paper 637.

https://digitalcommons.uri.edu/theses/637

This Thesis is brought to you for free and open access by DigitalCommons@URI. It has been accepted for inclusion in Open Access Master's Theses by an authorized administrator of DigitalCommons@URI. For more information, please contact digitalcommons-group@uri.edu. 


\section{A CROSS-SECTIONAL ANALYSIS OF}

BRONCHODILATOR PRESCRIBING IN COPD AND

CARDIOVASCULAR COMORBIDITY

BY

DAMILOLA ADESANOYE

A THESIS SUBMITTED IN PARTIAL FULFILLMENT OF THE

REQUIREMENTS FOR THE DEGREE OF

MASTER OF SCIENCE

IN

PHARMACEUTCIAL SCIENCES

UNIVERSITY OF RHODE ISLAND

2015 


\section{MASTER OF SCIENCE THESIS}

OF

DAMILOLA ADESANOYE

\section{APPROVED:}

Thesis Committee:

Major Professor Cynthia Willey

Stephen Kogut

Liliana Gonzalez

Nasser H. Zawia DEAN OF THE GRADUATE SCHOOL 


\begin{abstract}
Background: Bronchodilators used to treat Chronic Obstructive Pulmonary disease have been associated with adverse cardiovascular events. Moreover, the high prevalence of cardiovascular diseases (CVD) in COPD (8-40\%) requires an evaluation of treatment differences between comorbid groups in order to understand the appropriateness of drug prescribing.
\end{abstract}

Objective: To determine whether COPD patients with concurrent CVD are less likely to be prescribed bronchodilators compared to those without CVD.

Methods: A retrospective cross-sectional study was conducted using the 2010 National Ambulatory Medical Care Survey (NAMCS) to quantify the association between concurrent CVD morbidity and the probability of receiving a bronchodilator prescription. Visits included patients $\geq 40$ years who had COPD diagnosis. Surveyweighted data were analyzed through descriptive analysis, univariate (unadjusted) and multivariate (adjusted) logistic regression models. Demographics, patient, physician and visit characteristics were assessed as covariates in the models.

Results: Out of $11,627,061$ ambulatory visits recorded by patients $\geq 40$ years with COPD diagnosis, majority was male (57\%), non-Hispanic White $(80 \%)$ and used at least one bronchodilator $(55.5 \%)$. We found that a significantly lower proportion of the COPD-CVD group (32.3\%) was treated with bronchodilators versus $57.6 \%$ for the non-comorbid group. The effect of CVD on bronchodilator prescribing was modified by gender, beta-blockers and asthma. CVD patients who were female, not prescribed beta-blockers and not having concomitant asthma were $94 \%$ less likely to be prescribed bronchodilators compared the non-CVD females with the same 
characteristics. On the other hand, males not prescribed beta-blockers and not having concomitant asthma had $68 \%$ lower probability when CVD coexisted with COPD. Female CVD patients prescribed beta-blockers and not living with asthma had only a $20 \%$ chance of being a bronchodilator user than those without CVD. Cardiovascular disease did not affect the utilization of bronchodilators in males taking beta-blockers who either had or did not have asthma.

Conclusion: Concurrent CVD diagnosis is a significant factor for reducing the probability of prescribing bronchodilators for COPD and our findings provide evidence of variations in bronchodilator prescribing for stratified groups of COPDCVD patients. Most patients with COPD and CVD are less likely to be prescribed bronchodilators, with the exception of males who were also prescribed beta-blockers. Thus, this study highlights a specific patient subgroup for whom the guidelines are less likely to be observed. 


\section{ACKNOWLEDGMENTS}

I would like to thank my major professor, Dr. Willey for her continuous mentorship and supervision. Her thoughtful and practical advice was appropriate and concisely delivered to keep me focused and on track during the preparation of this thesis. Dr. Willey's class on advanced epidemiologic methods was crucial to being able to design and conduct the current pharmacoepidemiologic study.

I am thankful to have a thesis committee that is dedicated to my success as a graduate student and professional. I feel lucky to have the opportunity to learn from Dr. Kogut, Professor of Pharmacoeconomics and Health systems. His support to attend scientific conferences has been instrumental to exposing me to the outcomes research field. My outside committee member from the Statistics Department, Dr. Gonzalez provided timely and unreserved assistance in making my research work better.

I acknowledge the tremendous support and love from my family and friends. Special thanks to my parents Jose and Margaret Adesanoye and siblings (Ade, Sanmi and Tobi), who sacrificed personal comfort and faithfully committed resources in order to sponsor my education. I appreciate my friends that provided practical help, prayers and encouragement to strengthen me in many ways - Femi, Wen, Jing, Enoch, Mohan, Kehan, Rick, Doris, and Harvey. You have shown me that distance, nationality, age or gender differences are not confounders to building great relationships.

I owe my greatest appreciation to God Almighty who has bestowed his unfailing love and divine grace on me. He has been my faithful companion, friend, teacher, provider and inspiration in all endeavors, including this research project. 


\section{TABLE OF CONTENTS}

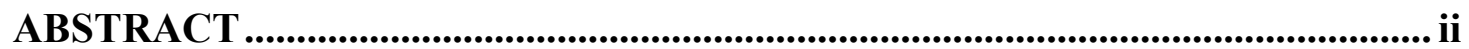

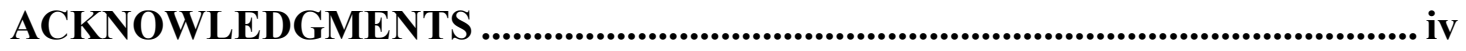

TABLE OF CONTENTS................................................................................ V

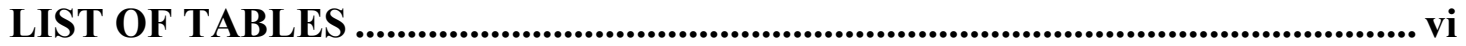

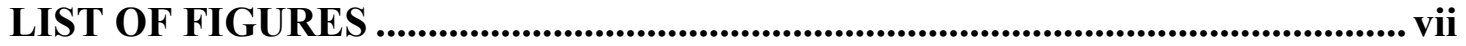

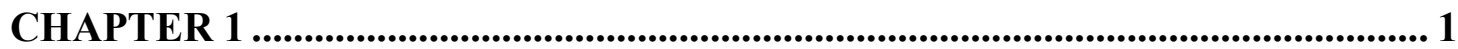

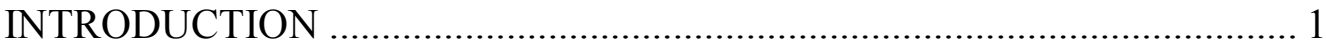

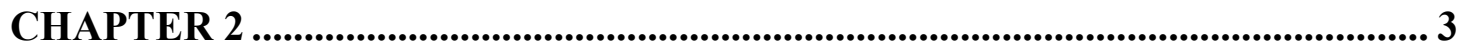

REVIEW OF LITERATURE ........................................................... 3

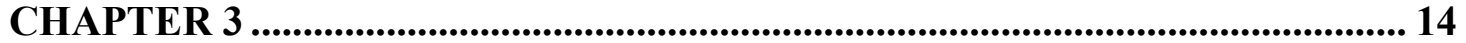

METHODOLOGY ........................................................................ 14

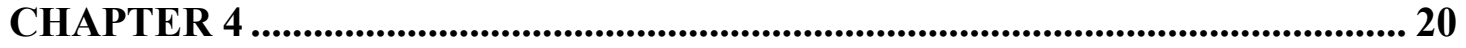

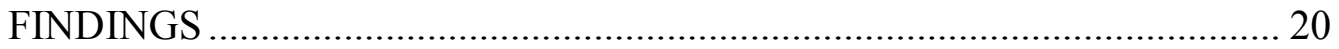

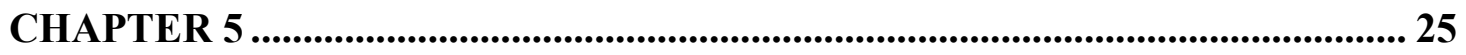

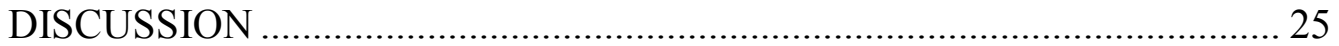

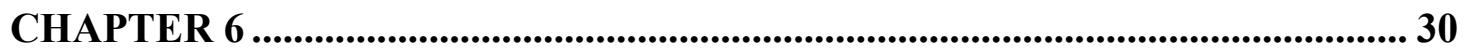

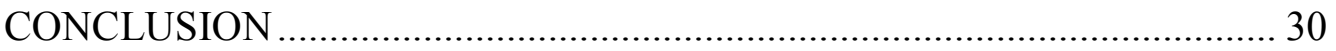

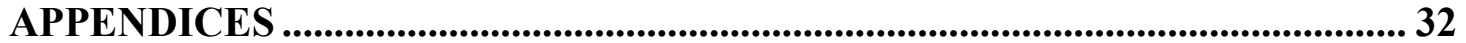

Appendix A: University of Rhode Island IRB Exemption Letter................... 32

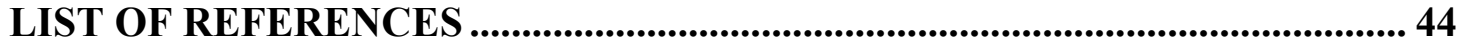

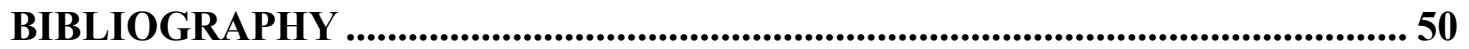




\section{LIST OF TABLES}

TABLE

PAGE

Table 1. Selected Information on the 2010 NAMCS Data and Analytic Sample.33

Table 2. ICD-9-CM diagnosis codes for COPD and cardiovascular diseases ..... 34

Table 3. List of NAMCS 2010 Pharmacologic classes and codes of bronchodilator

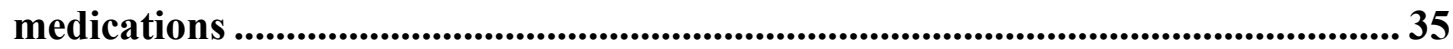

Table 4. Demographic and Clinical characteristics of COPD visits ..................... 36

Table 5. Utilization of bronchodilator by CVD status ......................................... 37

Table 6. Univariate logistic regression analysis....................................................... 38

Table 7. Modification of the effect of cardiovascular disease comorbidity on

bronchodilator prescription in COPD ......................................................... 39

Table 8. Multivariate Logistic Regression Analysis without effect modification 40 


\section{LIST OF FIGURES}

FIGURE

PAGE

Figure 1. Flow Chart of application of study eligibility criteria.......................... 41

Figure 2. Two-way contingency table for Primary IV and DV .......................... 42

Figure 3. Parametric Assessment of Continuous Variables................................ 43 


\section{CHAPTER 1}

\section{INTRODUCTION}

Chronic Obstructive Pulmonary Disease (COPD) is defined as a "preventable and treatable disease characterized by persistent airflow limitation that is usually progressive and associated with an abnormal inflammatory response of the lung to noxious particles or gases. Exacerbations and comorbidities contribute to the overall severity in individual patients." 1 The disease is clinically diagnosed as one or more of 3 subtypes - chronic bronchitis, emphysema and chronic airway obstruction. ${ }^{2}$

COPD is the fourth leading cause of chronic morbidity and mortality in the United States affecting $6.5 \%$ of adults (13.7 million diagnosed cases) and leading to 133,575 deaths. $^{2}$ In 2010 , there were 10.3 million physician office visits, 1.5 million emergency department visits, and 699,000 hospital discharges for COPD. ${ }^{2}$ Globally, COPD ranked fifth cause of years lived with disability (YLDs) in the 2010 global burden of disease study. ${ }^{3}$ The World Health Organization predicts that COPD will become the third leading cause of death worldwide by $2030 .{ }^{4}$ Inevitably, COPD is and will continue to be a major global health problem. ${ }^{5}$

Bronchodilators are the mainstay for symptomatic treatment of COPD due to their ability to relieve bronchial obstruction and airflow limitation, improve emptying of the lungs and reduce hyperinflation during rest and exercise. ${ }^{6,7}$ Three major classes are recommended as first-line agents - beta-( $\beta$ ) 2-agonists, anticholinergics (AC), and methylxanthines, used alone or in combination or as single or combination drugs. ${ }^{7}$ 
Despite the benefits of bronchodilator agents in the treatment of COPD, patients may be at an increased risk of cardiovascular (CV) toxicity due to beta-adrenergic stimulation. Previous studies showing an association between bronchodilators and adverse cardiovascular events such as arrhythmias, myocardial ischemia, heart failure and sudden cardiac death, will be discussed in detail in the literature review section. ${ }^{8-13}$

The potential cardiovascular risk of bronchodilators in COPD has important therapeutic implications for two main reasons: First of all, the prevalence of cardiovascular-related diseases (CVD) in COPD is estimated to range from $8 \%$ to as high as $40 \%{ }^{1,14-16}$ making it the most frequent and most important disease group coexisting with COPD. Secondly, the exclusion of comorbid subjects from clinical trials often limits the use of trial data in providing practical treatment recommendations for the real world COPD patient population where multiple morbidities are highly prevalent.

We hypothesize that cardiac disorders play an independent role in the lesser probability of receiving a bronchodilator prescription for COPD. The objective of this study is to provide descriptive data on the classes of bronchodilator medications prescribed to ambulatory patients with diagnosed COPD in the United States and examine whether COPD patients with CVD are less likely to be prescribed bronchodilators compared to COPD patients without CVD. 


\section{CHAPTER 2}

\section{REVIEW OF LITERATURE}

\section{Etiology and Epidemiology of COPD and its Comorbidities}

Cigarette smoking is the dominant and best-studied risk factor for COPD, though a substantial burden of disease occurs in nonsmokers. ${ }^{17-19}$ Other etiologic factors such as advanced age, occupational exposure to dust, fumes and gases, indoor and outdoor air pollution, airway hyper-responsiveness, asthma, infections and genetic predisposition ( $\alpha$-antitrypsin deficiency) are also important. ${ }^{1}$ Furthermore, it has been increasingly recognized that COPD is more than just a lung disease: it is a complex heterogeneous systemic disease, frequently associated with other chronic diseases including coronary heart disease, cardiovascular, respiratory tract, metabolic, hematological, musculoskeletal, gastrointestinal, renal diseases, psychiatric disorders and neoplasias. ${ }^{14,15,20-23}$

The prevalence of comorbidity in COPD has been studied using nationallyrepresentative data, National Health and Nutrition Examination Survey (NHANES) $1999-2008 .^{24}$ Using a ten-year analytic sample of 14,828 subjects (995 COPD cases)

aged $\geq 45$, subjects with self-reported physician diagnosis of COPD were more likely than subjects without physician-diagnosed COPD to have coexisting arthritis $(54.6 \%$ vs. $36.9 \%)$, depression (20.6\% vs. $12.5 \%)$, osteoporosis (16.9\% vs. $8.5 \%)$, cancer (16.5\% vs. $9.9 \%)$, coronary heart disease $(12.7 \%$ vs. $6.1 \%)$, congestive heart failure $(12.1 \%$ vs. $3.9 \%)$, and stroke $(8.9 \%$ vs. $4.6 \%){ }^{24}$ 
Vanfleteren and colleagues used a cluster analysis approach to assess the prevalence and severity of objectively identified chronic concomitant disorders in a cohort of 213 patients with moderate to very severe COPD. ${ }^{25}$ The CIRO COmorbidity (CIROCO) study was an observational single-center study and almost all subjects $(97.7 \%)$ had one or more comorbidities. More than half $(53.5 \%)$ of the patients had at least four comorbidities.

Another study in a sample of COPD patients referred to an Australian outpatient hospital-based pulmonary rehabilitation program reported that $96 \%$ of patients had at least 1 other chronic conditions and $29 \%$ had 5 or more comorbidities. ${ }^{26}$ Data were available on 70 patients and $64 \%$ of patients had multiple morbidities associated with cardiovascular disease.

While it is likely that the prevalence of comorbidities in people with COPD is influenced by common risk factors, such as smoking, advanced age, chronic systemic inflammation, physical inactivity and low socioeconomic status, studies have confirmed that concurrent conditions worsen health outcomes independent of preexisting risk factors. ${ }^{26}$ Comorbidities in COPD lead to lower health-related quality of life, ${ }^{27,28}$ more hospitalizations, severe disabilities ${ }^{5}$ and higher rates of mortality ${ }^{29,30}$ compared to those without comorbidities.

\section{Burden of comorbid COPD and Cardiovascular disease (CVD)}

Observational studies indicate that COPD is associated with a high prevalence of coronary artery disease, cardiac arrhythmias, cerebrovascular disease, peripheral vascular disease and congestive heart failure. ${ }^{31-33}$ In addition, COPD patients with 
CVD pose significantly higher clinical and economic burden on patients and healthcare system than COPD patients without CVD.

One large retrospective cross-sectional survey involving 618,090 subjects quantified the association between COPD and diagnosis of CVD and stroke and revealed that COPD was associated with a fivefold increase in the odds of having had CVD (OR 4.98, 95\% CI 4.85 to 5.81; $\mathrm{p}<0.001$ ), and a threefold increase in the odds of having had a stroke (OR 3.34, 95\% CI 3.21 to 3.48; $<<0.001$ ). ${ }^{34}$

Curkendall and colleagues found that the prevalence of all cardiovascular diseases was higher in the COPD group than in the comparison group subjects $(\mathrm{n}=11,493)$ in a retrospective cohort study in Saskatchewan longitudinal health care databases in Canada. ${ }^{35}$ After adjusting for cardiovascular risk, odds ratios of prevalence were: arrhythmia 1.76 (CI: 1.64-1.89), angina 1.61 (CI: 1.47-1.76), acute myocardial infarction 1.61 (CI: 1.43-1.81), congestive heart failure 3.84 (CI: 3.564.14), stroke 1.11 (CI: 1.02-1.21), pulmonary embolism 5.46 (CI: 4.25-7.02). COPD patients also had an elevated risk of hospitalization and death (OR 2.7 CI: 1.82-2.36) due to cardiovascular causes. ${ }^{35}$ One limitation of the study was the lack of baseline smoking data which made it difficult to separate the cardiovascular effects of smoking, a major risk factor for both COPD and CVD, from the effects of COPD.

Similar results on the impact of comorbid COPD-CVD on healthcare utilization were obtained in a retrospective matched-cohort of 4594 patients each with COPD and CVD $\geq 40$ years of age using administrative claims data and propensity score technique for matching. ${ }^{36}$ The data source for this study was the IMS Lifelink Database containing medical and pharmacy claims data from over 100 different 
managed healthcare plans (encompassing over 60 million patients) in the United States. The COPD-CVD cohort was about twice as likely than the COPD-only cohort to require COPD-related hospitalization (OR 1.95; $\mathrm{p}<0.001$ ), 47\% more likely to have an ER visit (OR 1.47; $\mathrm{p}<0.001)$ and $62 \%$ more likely to require hospitalization and/or ER visit $(\mathrm{OR}, 1.62 ; \mathrm{p}<0.001) .{ }^{36}$ Significant differences in healthcare costs were found as the average annual all-cause medical costs per patient were $\$ 22,755 \mathrm{vs}$ $\$ 8,036(\mathrm{p}<0.001)$, and total costs were $\$ 27,032$ vs $\$ 11,506(\mathrm{p}<0.001)$, for COPD-CVD and for COPD-only groups respectively. ${ }^{36}$ Corresponding average COPD-related annual medical costs were $\$ 1891$ vs $\$ 1060(\mathrm{p}<0.001)$ and total costs were $\$ 3295$ vs $\$ 2379(\mathrm{p}<0.001)$.

\section{$\underline{\text { COPD Treatment }}$}

The most widely applied guideline for treatment is the Global Strategy for the Diagnosis, Management, and Prevention of COPD (GOLD strategy), revised in 2014 containing summaries of current evidence on management and prevention strategies. ${ }^{1}$ Four grades of disease are defined according to severity of airflow obstruction; mild disease A (FEV1 $\geq 80 \%$ predicted), moderate disease B $(50 \% \leq \mathrm{FEV} 1<80 \%$ predicted), C severe disease $(30 \% \leq \mathrm{FEV} 1<50 \%)$, and very severe disease D (FEV1 $<30 \%$ predicted); and the result of this classification leads to treatment choice.

Pharmacotherapy constitutes the major intervention used in COPD patients. Medications commonly used for COPD are bronchodilators, corticosteroids and phosphodiesterase-4 inhibitors. ${ }^{37}$ None of the existing medications have been proven to change long-term decline in lung function, as such, the main goal of 
pharmacological therapy is to reduce symptoms, decrease the frequency and severity of exacerbations, improve quality of life and exercise tolerance. ${ }^{1}$

Non-pharmacological treatment modalities include pulmonary rehabilitation, oxygen therapy, ventilation support and surgical treatments. ${ }^{1}$ Regardless of disease stage, the identification and reduction of risk factors are important in COPD prevention and treatment. Smoking cessation is the first and most crucial step in COPD therapy for all COPD patients who smoke, and has greatly influenced the natural history of COPD and lowered mortality with long-term quit rates as high as $25 \% .{ }^{1}$ Use of smoking cessation products (Bupropion, Varenicline and Nortriptyline) combined with behavioral support is reported to increase successful smoking cessation compared with either intervention alone. ${ }^{1,37}$

\section{$\underline{\text { Safety of Bronchodilators in COPD }}$}

Bronchodilators are the mainstay for symptomatic treatment of COPD due to their ability to relieve bronchial obstruction and airflow limitation, improve emptying of the lungs and reduce hyperinflation during rest and exercise. ${ }^{6,7}$ Bronchodilator treatments include beta-( $\beta$ ) 2-agonists, anticholinergics (AC), and methylxanthines, used alone or in combination. They are recommended as first-line agents useful to prevent or reduce symptoms as-needed or on a regular basis. ${ }^{7}$ Short-acting bronchodilators are typically used as rescue medication for immediate symptom relief, routinely in the early disease stages or in COPD patients with a low symptom burden whereas long-acting bronchodilators are used as regular maintenance therapy and are generally more effective and convenient. ${ }^{7}$ Combinations of bronchodilators may improve efficacy and 
reduce risk of adverse effects rather than increasing the dose of a single agent. ${ }^{7}$ Inhaled bronchodilators are preferred over oral preparations based on favorable efficacy and side effect profile. ${ }^{1}$

Despite the benefits of bronchodilator agents in the treatment of COPD, patients may be at an increased risk of cardiovascular (CV) toxicity due to beta-adrenergic stimulation. Evidence on the safety of bronchodilator therapy in COPD is mixed. There have been reports on the relative safety of bronchodilator use in COPD ${ }^{38}$ whereas some researchers have found clinically significant higher risks in the incidence of cardiovascular events in patients on selected bronchodilator agents than control groups. ${ }^{8,11,12,39,40}$

In 2003, Ferguson and coworkers ${ }^{38}$ evaluated the cardiovascular safety of salmeterol (a beta-2-agonist), in COPD patients by reviewing safety data from randomized, double-blind, parallel group, multiple-dose studies. Pooling results from 7 clinical trials, the authors concluded that though both salmeterol and placebo groups had an increased incidence of adverse $\mathrm{CV}$ events with age, concurrent cardiovascular conditions, and treatment with antiarrhythmic/bradycardic agents, the incidence of cardiovascular events (8\%), including cardiovascular deaths, was similar in both groups.

However, a meta-analysis of randomized placebo-controlled trials of beta-2 agonists in patients with obstructive airway disease (asthma and COPD) performed a year later, revealed opposite results. ${ }^{39}$ This study included longer duration trials in the analysis to evaluate both the short-term effect on heart rate and potassium concentrations, and the long-term outcome of adverse cardiovascular events. Adverse 
events included sinus and ventricular tachycardia, syncope, atrial fibrillation, congestive heart failure, myocardial infarction, cardiac arrest, or sudden death. From among 33 trials, the conclusion was that beta- 2 agonist treatment significantly increased the risk for a cardiovascular event (relative risk RR 2.54; 95\% CI, 1.59 to 4.05) compared to placebo mainly because of the short term effects of tachycardia and hypokalemia.

In 2008, Macie et $\mathrm{al}^{8}$ examined the relationship between use of inhaled respiratory drugs in people with chronic obstructive respiratory diseases and cardiovascular hospitalizations for 5years from 1996 through 2000 using the Manitoba Health Database. The nested case control study included exposure to beta agonists, anticholinergic (ipratropium bromide), and inhaled corticosteroids (ICS) and outcomes were first hospitalizations for supraventricular tachycardia, myocardial infarction, heart failure or stroke. The likelihood of a hospitalization for SVT, MI, and HF was significantly increased for those to whom beta agonists [OR 1.68, 95\% CI 1.41-2.00], ipratropium [OR 1.48, 95\% CI 1.29-1.70] but not ICS [OR 1.13, 95\% CI 0.95-1.35] were dispensed within 60 days prior to the hospitalization. While it is likely that bronchodilator use was simply a marker of disease severity and this accounted for their association with cardiovascular disease, the authors note that ICS was not associated with these outcomes. The findings on specific drug interactions were that each case the receipt of cardiac drugs decreased the likelihood of hospitalizations associated with bronchodilator. For example, bronchodilators increased the risk of stroke in patients who were not taking cardiac drugs but did not increase the risk of arrhythmia in the presence of anti-arrhythmic agents. 
In 2012, another nested case-control study involving 6018 subjects with COPD from the Saskatchewan Cohort Study ${ }^{9}$ found that the rate of arrhythmia was elevated with the new use of ipratropium, a short-acting anticholinergic agent (RR 2.4; 95\% CI, 1.4-4.0) and of long-acting $\beta$-agonists (RR, 4.5; 95\% CI, 1.4-14.4). The researchers did not find an elevated risk with short-acting beta-2-agonists or methylxanthines and proceeded to ascertain the results in a larger patient pool. For the reassessment, the larger Quebec cohort of 76,661 subjects was analyzed. ${ }^{10}$ They found that the rate of arrhythmias increased with the new use of short-acting beta-2-agonists (RR, 1.27, 95\% CI, 1.03-1.57) and long-acting beta-2-agonists (RR 1.47; 95\% CI, 1.01-2.15), but not with ipratropium and methylxanthines. This slightly increased risk for short-acting beta-2 agonists and ipratropium corroborates evidence earlier obtained from the Manitoba Health Database. ${ }^{8}$

Tiotropium, a once daily long-acting anticholinergic bronchodilator has also been reported for safety concerns regarding its use in the COPD patient population. In 2013, Singh et ${ }^{13}$ reported that an increased risk of all-cause mortality (RR 1.52; 95\% CI, 1.06-2.16) and CVD mortality (RR 2.05; 95\% CI, 1.06-3.99) was associated with tiotropium use. Patients with known cardiac disease were also reported to have significantly high risk of dying from cardiac causes though the risk estimates largely varied among patients (RR 8.6; 95\% CI, 1.1-67.2).

In 2011, a retrospective cohort study of patients attending a Heart Failure (HF) Disease Management Programme was done by Bermingham and colleagues. ${ }^{11}$ The cohort size was 1294 patients (age $70.6+11.5$ years) of whom 64\% were male and $22.2 \%$ were taking $\beta 2$ agonists. The mean follow-up was $2.9+2.4$ years. The study 
intended to address gaps in literature that did not consider the influence of factors such as the dose, duration, or type of bronchodilator therapy (long acting vs. short acting) on outcomes. The primary endpoint was the effect of $\beta 2$ agonist use compared with no $\beta 2$ agonist use on mortality using unadjusted and adjusted Kaplan2Meier survival curves. Beta-agonist users were older, more likely to be male, to have smoked, to have chronic obstructive pulmonary disease (COPD) and asthma, and less likely to take beta-blockers. Unadjusted mortality rates for $\beta 2$ agonist users were found to be significantly higher than non- $\beta 2$ agonist users [hazard ratio (HR) 1.304, 95\% CI $1.030-1.652, \mathrm{P}=0.028]$. Overall mortality rates were similar [HR $1.043,95 \% \mathrm{CI}$ (0.771-1.412), $\mathrm{P}=0.783$ ] after adjusting for covariates like age, sex, beta-blocker use, co-morbidity, smoking, COPD, and differences in B-type natriuretic peptide (BNP). There was no influence of $\beta 2$ agonist duration of use, dose, or type on outcome in fully adjusted models.

The possible role of the mode of administration of bronchodilators in observed differences in treatment effects has also been explored. Available formulations include metered dose inhalers (MDI), dry powder inhalers (DPI) and soft mist inhalers (SMI). Using a retrospective study, Verhamme and colleagues ${ }^{12}$ investigated the risk of mortality between tiotropium Respimat (an SMI) vs Handihaler (DPI) and showed that the use of Respimat was associated with about 30\% increased mortality (adjusted HR 1.27; 95\% CI, 1.03-1.57) compared with Handihaler and the association was strongest for cardiovascular /cerebrovascular death (adjusted HR 1.56, 95\% CI 1.08-2.25). The reason for this apparent elevated risk is not clear, though it may be related to rapid peak drug concentrations achieved after mist inhalation. ${ }^{40}$ 
The publications on safety of bronchodilators reveal the likelihood of different study designs to bias and confounding. Smoking status, non-respiratory drugs with known arrhythmogenic properties taken concomitantly may bias the study results. The adverse cardiovascular outcomes may reflect COPD severity or confounding by indication rather than an adverse effect of bronchodilator therapy. It is also possible that bronchodilators impose a larger relative risk in people with undiagnosed cardiovascular disease than in people with known disorders since bronchodilators did not increase the risk of arrhythmia in the presence of anti-arrhythmic agents.

\section{$\underline{\text { Utilization of Bronchodilators }}$}

Although, long-term decline in lung function is irreversible in COPD, bronchodilators are recommended to reduce airflow obstruction, reduce the frequency of exacerbations, improve health status and decrease mortality. ${ }^{1}$ Therapy usually includes a short-acting bronchodilator or a long-acting bronchodilator (either a Beta-2agonist or an anticholinergic drug or a methylxanthine) or combination products for adequate clinical response and tolerance of side effects. ${ }^{1}$

A case-control study was conducted on the use of bronchodilators and arrhythmias in COPD in 2012. ${ }^{9}$ Out of 469 cases of arrhythmias, the proportion taking at least one short-acting $\beta$-agonist was $37.9 \%$, long-acting $\beta$-agonists $1.9 \%$, Ipratropium bromide $29.4 \%$ and Methylxanthine $10.2 \%$ compared to the controls where use was short-acting $\beta$-agonist was $35.2 \%$, long-acting $\beta$-agonists $1.6 \%$, Ipratropium bromide $22.2 \%$ and Methylxanthine $8.7 \%$. The percentage of $\beta$-blocker users in the study sample was $11.6 \%$ and overall cardiovascular medication prescribed 
is $22.4 \%$. Groenwold and colleagues described the characteristics of a cohort of 3376 COPD/ asthma patients that were beta-agonist users and non-users. ${ }^{41} 47.5 \%$ were female, $16.7 \%$ of the medication users had diagnosed cardiovascular disease, $29.1 \%$ utilized beta-agonist and $16.7 \%$ had prescriptions for anticholinergic drugs.

In addition to the relationship between bronchodilators and cardiovascular disease in COPD, evidence that medication prescribing may differ by patient demographic characteristics exists. Treatment differences by sex in the utilization of bronchodilators and other COPD medications were investigated in a cross-sectional analysis based on 10 year data from two national datasets - National Ambulatory Medical Care Survey (NAMCS) and the National Hospital Ambulatory Medical Care Survey (NHAMCS). ${ }^{42}$ Women had a consistently higher proportion of visits with COPD medication prescriptions than visits by men. The frequency of COPD medications prescribed to women decreased by $7 \%$ (from $73 \%$ to $67 \%$ ) during the study period (1995-2004). The average number of COPD drug mentions per visit decreased for both women and men and trends were significantly different between men and women $(P<0.001)$. Prescription of methylxanthines decreased in visits by women and men, whereas prescription of anticholinergics increased continuously in the recent years.

Certainly, the high prevalence of COPD and cardiovascular disease warrant further study of prescribing patterns in COPD patients with cardiac conditions. Thus, the purpose of the present study is to determine whether COPD patients in ambulatory care in the United States have a lower likelihood of being prescribed bronchodilators if they have concurrent CVD compared to those without CVD. 


\section{CHAPTER 3}

\section{METHODOLOGY}

\section{$\underline{\text { Data Source }}$}

The 2010 National Ambulatory Medical Care Survey (NAMCS) ${ }^{43}$ was the source of data used to assess COPD patient visits. The NAMCS is designed to collect data on outpatient visits from non-federally employed office-based physicians in the United States and it is conducted annually by the National Center for Health Statistics (NCHS), a division of the Centers for Disease Control and Prevention (CDC). The survey employs multistage probability sampling design to generate unbiased national estimates. These data are weighted to be nationally representative of outpatient doctor visits throughout the United States.

The unit of data collection is the visit or encounter not patient-level. NAMCS data contains variables on reason for visit, diagnoses, diagnostic/screening services provided, medication therapy, demographic characteristics of patients, specialty of physician seen, and certain characteristics of the facility, such as geographic region and metropolitan status for a randomized sample of patient visits during a randomly selected 1-week time period. The NAMCS has gained enormous popularity as a choice dataset to assess national trends in ambulatory medical care utilization and examine concordance of prescribing patterns with evidence-based treatment guidelines.

Therefore, we consider the dataset suitable for this analysis. The 2010 NAMCS data were used because they were the most recently available. 
The Institutional Review Board of the University of Rhode Island recognizes that studies using de-identified, publicly available data do not constitute human subjects research and granted exempt status for this study.

\section{$\underline{\text { Analytic sample }}$}

The study population consisted of patients aged 40 years and over, who had visits where chronic obstructive pulmonary disease (COPD) was diagnosed. A patient visit was included if the COPD International Classification of Diseases, 9th revision, Clinical Modification ICD-9-CM codes 491, 492 and 496 were listed as 1 of 3 diagnoses for that visit. COPD visits were compared to number of 'Yes' responses to the question "Does the patient now have COPD (Yes/No)" captured on the patient record form. Figure 1 depicts the inclusion and exclusion criteria.

Further stratification of COPD sub-groups was done by presence or absence of concurrent diagnosis of cardiovascular conditions of interest. Based on previous studies, the following cardiovascular diseases were selected: myocardial infarction, angina, coronary artery disease, cardiac arrhythmias (including tachycardia, atrial fibrillation, and cardiac arrest), and congestive heart failure. The ICD-9 diagnosis codes are presented in Table 2.

\section{$\underline{\text { Variables Specification }}$}

The dependent variable is defined as the prescription of a bronchodilator at a visit $(\mathrm{Rx}=1$ or 0$)$. New or continued bronchodilators recorded in any of the 32 therapeutic class fields were identified using the therapeutic class codes extracted from 
NCHS's Ambulatory Care Drug Database. Table 3 shows the relevant drug codes. The drug visits strategy was used instead of drug mentions because we are interested in a binary response per visit (any bronchodilator treatment $\mathrm{Rx}=1$ vs no bronchodilator treatment $\mathrm{Rx}=0$ ) not the total number of times bronchodilators are mentioned in the entire study population, which was more than one bronchodilator medication for each ambulatory medical care visit, on the average.

Bronchodilator users were stratified into 4 therapeutic categories (beta- $(\beta)$ 2agonists, anticholinergics (AC), methylxanthines and combination bronchodilators) to estimate the proportion of users in each subclass and compare bronchodilator therapy across CVD exposure variable and other visit characteristics. Table 3 outlines the commercially available bronchodilator medications according to pharmacological classes. It should be noted that all bronchodilator-containing drugs whether single agents or in combination with corticosteroids were included in the outcome variable definition.

The independent variable of interest is CVD status $(\mathrm{Dx}=1$ or No $\mathrm{Dx}=0)$. Age was modeled as a continuous variable. All other explanatory variables (confounders/effect modifiers): tobacco smoking, physician specialty, type of healthcare insurance, use of inhaled corticosteroids, cardiac medications (antiarrhythmic and beta-blockers) and asthma were measured as categorical variables.

Some study covariates had to be re-coded by removing unknown or missing responses, collapsing/combining categories and dummy coding. Categorical independent variables were dummy coded as follows: Race/ethnicity was recoded into 4 groups as Non-Hispanic White (0), Non-Hispanic Black (1), Hispanic (2) and Non- 
Hispanic Other (3). Tobacco use was recoded into Non-current (0) and Current (1). Use of selected medications including inhaled corticosteroids, antiarrhythmic drugs and beta-blockers were recoded into No (0) and Yes (1) values. Health insurance coverage was collapsed into 4 categories and dummy coded - Medicare (0), Private insurance (1), Medicaid (2) and Other (3). The last group combined other sources of payment like self-pay, worker's compensation, no Charge/Charity. Similarly, physician specialty initially presented as 15 groups was collapsed into 4 groups since some specialties had no or very few COPD patient visit to have meaningful interpretation. General/Family Practice, Internal Medicine, Cardiology and Other were the 4 dummy variables created.

\section{$\underline{\text { Parametric Assessment }}$}

A parametric assessment was done to determine if continuous independent variables satisfied the assumption of linearity in the logit. Age was the only continuous variable and was categorized into 3 groups 40-54, 55-74 and 75 \& over for the univariate logistic regression analysis. In the results obtained, the Odds Ratios followed a positive linear relationship with bronchodilator prescription across the different age groups (Appendix - Figure 3) and implies it can be coded as either a continuous or categorical variable. Age was modeled as a continuous variable for the purpose of this study.

\section{Descriptive Statistics and Modeling Strategy}


Descriptive statistics, univariate and multivariate techniques were used. All analyses were performed on weighted data as recommended by the NCHS. The patient visit weighting, as provided, uses the most recently available census data to provide a stratified representation of the nation's patient population. All statistical analyses were done using SAS version 9.3 and the results report weighted information.

For descriptive analysis, the means (with standard error) and proportions of demographic, clinical and medication utilization characteristics for the study population were calculated. Rates of drug visits were computed for the sub-categories of bronchodilator medications. Bivariate associations between the dependent variable (prescription of one or more bronchodilators) and each independent variable were separately estimated using univariate logistic regression to obtain unadjusted Odds Ratios and $95 \%$ confidence intervals. This will enable inferences to be deduced about the true population parameter lies between the confidence limits with $95 \%$ certainty.

Confounding and interaction were assessed given that they may bias the relationship between CVD morbidity and treatment with bronchodilators. Two multivariate logistic regression (LR) models were developed - one containing interaction terms plus confounding variables and the other without interaction (confounders only). First of all, interaction was tested by applying the hierarchy principle to combinations of variables. This implies that if certain interaction terms are significant, all lower order components of such terms cannot be deleted and will remain in any further models considered. Two-way interaction analysis was performed for the following pairs of variables: CVD and gender, CVD and beta-blockers, CVD and asthma. Here, the Odds Ratios of prescribing a bronchodilator for COPD in a 
CVD patient is described in terms of the modifying variable, either gender, betablockers or asthma. The multivariate logistic regression (LR) model without interaction terms was developed.

Both multivariate models included a number of confounders - Age, gender, race, insurance coverage, asthma, concomitant antiarrhythmic and beta-blocker use, and physician specialty. Therefore, the multiple regression analysis presented adjusted models and allowed us to quantify the true association between concurrent COPDCVD morbidity and the probability of receiving a bronchodilator prescription, while controlling for the effects of other explanatory variables.

\section{$\underline{\text { Model fit }}$}

The next step in the model building procedure was to verify whether or not the model fitted the data well. Hosmer and Lemeshow goodness-of-fit test and a likelihood ratio test were conducted on the two multivariate logistic models - full model with interaction and reduced model without interaction. A final model was selected based on the adequacy of the fit.

In interpreting the results of the likelihood of prescribing a bronchodilator for COPD visit of a patient with cardiovascular comorbidity, the Adjusted Odds Ratios derived from the selected multivariate logistic regression model were used. The 95\% confidence intervals were also calculated for each Odds Ratio. 


\section{CHAPTER 4}

\section{FINDINGS}

\section{Study Sample Characteristics}

An estimated 13,799,072 visits of patients above 40 years had a diagnosis of COPD occurred in 2010 in the US. This is approximately $1.4 \%$ of 1 billion annual office visits. Missing or unknown data were removed leaving 11,627,061 visits in the analytic sample (Table 4).

The majority of the population (57\%) was male, between 55 and 74 years (mean age, 69 years). Over $80 \%$ were Non-Hispanic White and only $8.3 \%$ had the cardiac comorbidities of interest. In terms of the dependent variable, $55.5 \%$ of the COPD visits had a bronchodilator prescription. Source of payment for most visits was reported to be Medicare (67.5\%) which is consistent with the average age $\geq 65$ years eligible for Medicare benefits. $14.4 \%$ had a concurrent diagnosis of asthma showing that some patients may be suffering from the asthma-COPD overlap syndrome. A small proportion of visits received a prescription for inhaled corticosteroids.

Concomitant use of cardiac medications like anti-arrhythmic agents and beta-blockers occurred in $14.3 \%$ and $23.4 \%$. Cardiologists had a lower percentage of the office visits compared to Internal Medicine doctors (22.5\%), Family physicians (29.4\%) and other specialties $(44 \%)$. 


\section{$\underline{\text { Univariate Logistic Regression }}$}

The univariate logistic regression analysis performed indicated that most of the independent variables were significantly associated with the dependent variable (Table 5). Of the 11,672,061 COPD visits, 55.5\% had a bronchodilator (BD) prescribed. CVD visits had lesser odds $(\mathrm{OR}=0.35,95 \% \mathrm{CI} 0.31-0.4)$ than non-CVD visits of receiving a prescription for a bronchodilator. Females had a lower chance of being prescribed a bronchodilator compared to males $\mathrm{OR}=0.5195 \% \mathrm{CI} 0.47-0.55)$. In terms of patient ethnicity, Hispanics and non-Hispanics blacks were about $24 \%$ and $78 \%$ less likely to have a bronchodilator medication than Non-Hispanic Whites because they had lower OR of $0.76(95 \% \mathrm{CI} 0.62,0.92)$ and $0.22(95 \% \mathrm{CI} 0.2,0.26)$ respectively. There was no significant treatment difference between non-Hispanic whites and non-Hispanics persons that were neither white nor black $(\mathrm{OR}=0.94,95 \%$ CI $0.74-1.19)$.

The effect of age on the likelihood of bronchodilator use was significant in the univariate regression analysis $(\mathrm{OR}=1.01,95 \%$ CI $1.01-1.02 \mathrm{p}=<0.0001)$. Odds Ratio of 1.01 implies that the chance of being prescribed the medication increases by $10 \%$ with every 10 years of increasing age. Surprisingly, current smokers were half as likely to be prescribed one or more bronchodilators compared to those who did not currently smoke $(\mathrm{OR}=0.5595 \% \mathrm{CI} 0.51-0.59)$. The most likely reason is that those who eventually developed COPD and were taking medications may have quit smoking and be in the 'not current' category. Again, the implication of the broad categorization of the tobacco use variable into 'Current' and 'Not current' smokers is that it excludes smoking behaviors like ex-smokers, never smokers, heavy or light smokers and we 
cannot compare treatment differences. There was a strong association between asthma and bronchodilator utilization as revealed by the odds ratio of $4.64,95 \%$ CI $4.07-5.3$.

The use of inhaled corticosteroids appears to increase the chance that patient is also taking a bronchodilator $(\mathrm{OR}=2.84,95 \% \mathrm{CI} 2.23$ - 3.63) while beta-blocker utilization decreased the probability of concomitant bronchodilator treatment $(\mathrm{OR}=0.88,95 \%$ CI $0.80-0.95)$. Antiarrhythmic drugs were not associated with prevalent $\mathrm{BD}$ use $(\mathrm{OR}=1.02,95 \%$ CI $0.92-1.13)$

Physician specialty and type of insurance were associated with increased odds of receiving a bronchodilator during a doctor visit ( $\mathrm{p}$-value $<0.001)$. A patient who had private insurance $(\mathrm{OR}=1.12,95 \% \mathrm{CI} 1.02-1.21)$ or was seen by a cardiologist $(\mathrm{OR}=$ $1.32,95 \%$ CI $1.09-1.59)$ or other specialty $(\mathrm{OR}=2.13,95 \% \mathrm{CI} 1.95-2.33)$ was more likely to get a BD prescription compared to those in the reference category who had Medicare coverage or were seen by a family doctor or internal medicine specialist $(\mathrm{OR}=1.00)$. Medicaid enrollees did not differ in their treatment with bronchodilators for COPD diagnosis $(\mathrm{OR}=1.09,95 \% \mathrm{CI} 0.91-1.31)$.

\section{$\underline{\text { Multivariate Logistic Regression }}$}

Two multivariate logistic regression (LR) models were developed - one containing interaction terms, exposure and other independent variables and the other without interaction (exposure plus independent variables only).

In the interaction model, the effects were significant between CVD and each of three possible modifying variables tested - gender, beta blockers (BB) and asthma since 
all $\mathrm{p}$-values $<0.05$. All three modifiers and their product terms with CVD were retained in the model according to the hierarchy principle.

The reduced model without interaction terms contained the exposure variable (CVD), and potential confounding variables yielded the results in Table 8. A likelihood ratio test was conducted based on the null hypothesis of 'no interaction' versus 'interaction' as alternative hypothesis. The test statistic was 134.4 , p-value $<0.0001$ produced evidence that the 'interaction' model is a significantly better fitting model. Therefore, the interaction model was selected as the best model and this final choice guided the interpretation of the parameter estimates and odds ratios. Table 7 displays the Odds Ratio for the modifying effect of gender, asthma and $\beta$-blockers on the association between CVD and bronchodilator prescribing in COPD.

For effect modification by gender, CVD had a greater effect on bronchodilator prescribing compared to the non-CVD group in females with neither asthma nor betablocker medication. $\mathrm{OR}=0.06,95 \% \mathrm{CI} 0.04-0.09$ implies a $94 \%$ reduction in the probability of receiving bronchodilator. In males with no asthma and no beta-blocker utilization, the effect of CVD was $68 \%$ since $\mathrm{OR}=0.32,95 \% \mathrm{CI} 0.25-0.40$. The highest difference in the odds of bronchodilator use between CVD and non-CVD groups was observed in females who had asthma and did not use beta-blockers (OR=0.03, 95\% CI 0.02-0.06). Thus, this patient group had the least chance of taking bronchodilators.

CVD was not associated with bronchodilator prescribing in male beta-blocker users, regardless of asthma status (for male, BB users with asthma $\mathrm{OR}=0.6295 \% \mathrm{CI}$ 0.33-1.16; for male BB users without asthma OR=1.11 95\%CI 0.82 - 1.51). Therefore, cardiovascular disease did not affect the outcome in this category of patients. On the 
contrary, CVD female beta-blocker users without asthma had $79 \%$ less probability of receiving a bronchodilator than similar patients without CVD.

The effect of cardiovascular disease was also modified by concomitant asthma to different degrees. CVD asthma patients who were males and not taking BB were only $17 \%$ as likely to be prescribed bronchodilators compared to those without CVD, that is, $83 \%$ less chance of receiving the drug. The effect of CVD was stronger for female asthma patients taking BBs with $89 \%$ lower likelihood, and strongest for female asthma patients who did not use BB (97\% lower likelihood). 


\section{CHAPTER 5}

\section{DISCUSSION}

Our study revealed that $\boldsymbol{\beta}$-agonists were the most frequently prescribed class of bronchodilators and were prescribed at $56.4 \%$ of COPD visits. This fact supports previous studies. ${ }^{44}$ We conducted this cross-sectional study to determine whether prescribing rates of bronchodilators in COPD patients were different in cardiovascular comorbidities and if so, to what extent patient characteristics modified the prescribing pattern in ambulatory care in the United States.

We found that most COPD patients, who had been diagnosed with cardiovascular disease, were prescribed bronchodilators less frequently than were those who had COPD without cardiovascular diagnosis, but that this relationship was modified by patient characteristics. This pattern was more evident for females, whereas males had less pronounced differences between CVD and non-CVD groups. Our finding was consistent with literature on treatment differences in bronchodilator utilization for comorbid groups. ${ }^{45}$

There were significant interactions between cardiovascular disease and gender, $\beta$ blocker and asthma, shown in Table 7 . The presence of cardiovascular diagnosis significantly decreased the likelihood of bronchodilator prescription by $97 \%$ for females who were not taking beta-blockers but had asthma $(\mathrm{OR}=0.03,95 \% \mathrm{CI} 0.02$ 0.06). Males with similar characteristics had $83 \%$ reduced odds of taking bronchodilators. This was not entirely suspected as a previous cross-sectional study by 
Suh et al based on 10 years data from the NAMCS and hospital files (NHAMCS) ${ }^{42}$ found that women had a consistently higher proportion of visits with COPD medication prescriptions than visits by men.

No significant difference in bronchodilator utilization between CVD and non-CVD groups was observed with the use of beta-blockers in males who were either asthma $(\mathrm{OR}=0.6295 \% \mathrm{CI} 0.33-1.16)$ or non-asthma patients $(\mathrm{OR}=1.1195 \% \mathrm{CI} 0.82-1.51) . \mathrm{A}$ possible explanation may be that the concurrent use of beta-blockers for cardiac conditions and bronchodilators (which are majorly beta-agonists) in patients with multiple morbidities, leads to opposing pharmacological activity due to interaction between these medications. Other studies have found that the effects of $\beta$-agonists may be diminished by $\beta$-blockers and vice-versa. ${ }^{46}$ In the Cooperative Cardiovascular Project $^{47}, \beta$-blocker use was not associated with lower mortality among patients receiving concurrent beta-agonists. Subjects enrolled in the Veterans Administration's ACQUIP trial who received both beta-blockers and beta-agonists had no increase in risk of acute coronary syndromes. ${ }^{48}$ However, we did not observe this nullifying effect among females with comparable characteristics. The effect of CVD on bronchodilator prescribing in females taking beta-blockers with coexisting asthma was about $79 \%$ less than those without $\mathrm{CVD}(\mathrm{OR}=0.2195 \% \mathrm{CI} 0.14-0.30)$. These results point to the fact that the effect of CVD on prescribing differs between males and females who concurrently use beta-blockers and bronchodilators (mainly beta-agonists) and suggest more conservative prescribing practices for females than for males. 


\section{$\underline{\text { Strengths and Limitations }}$}

One of the strengths of the current study is the dataset. The NAMCS provides a national perspective on drug utilization in ambulatory medical care. We included patients with COPD diagnosis, race and ethnicity data, sources of payment, all regions and physician categories across the United States. Standard ICD-(-CM coding used for all the diagnoses aided identification of the COPD and cardiovascular conditions of interest. Apart from the ICD-9 codes, the survey included separate physician-defined variables for chronic conditions like COPD, Congestive heart failure, Ischemic heart disease. For example, the questions on the patient record form came in form of "Does the patient now have COPD (Yes/No)". We could compare responses from both approaches to increase the reliability of patients' diagnosis. The Ambulatory Drug database had specific drug codes for each therapeutic class which were employed for easy analysis of medication utilization for bronchodilators, cardiovascular drugs and their therapeutic subcategories. The inclusion of these details helped to evaluate differences in the use of bronchodilators across patient characteristics.

This study has limitations related to the study design and datasource. Because of the cross-sectional nature of the study design, the disease diagnosis and use of medications prescribed were collected at a single point in time, precluding the researcher from establishing the temporal relationship between onset of cardiovascular disease and initiation of bronchodilator treatment.

Bronchodilator prescriptions were assumed to be directly indicated for COPD treatment which may not be accurate. The NAMCS data has a comprehensive list of medications and diagnosis codes documented for each patient encounter but since there 
is no clear match between the prescribed medications and ICD-9 diagnosis codes, we could not verify the specific diagnosis for which bronchodilators are being prescribed. Future improvements to the survey design to establish a link between these disease condition and medications prescribed would be helpful to researchers. The dataset did not contain specific information that would indicate that patients may have a contraindication or past drug-related adverse event, thereby preventing the use of one or more bronchodilator medication.

Another limitation is the type of drug formulation. $17.4 \%$ of the prescribed products per visit were fixed combinations of different classes of bronchodilators or a bronchodilator in addition to an inhaled corticosteroid. However, we categorized and assessed them like any other bronchodilator in the study because evidence suggests inhaled corticosteroid present less cardiovascular risk unlike oral corticosteroids that may cause sodium and fluid retention leading to elevated blood pressure and adverse cardiovascular effects. ${ }^{49,50}$ Combination regimens are substantially utilized in COPD due to the increased effectiveness, reduced burden of medication use and increased adherence that can potentially achieved with this agents. Therefore, all bronchodilatorcontaining drugs whether single agents or in combination with corticosteroids were included in the definition of the outcome variable.

We considered including disease severity measures as covariates in this study but were unable to because the cross-sectional data did not contain clinical outcomes or follow-up information. Prescribing practices often differ from provider to provider and it may be worth investigating predictors of bronchodilator prescribing among physicians. Future research should attempt documenting the physician characteristics 
influencing bronchodilator prescribing for COPD patients. The outcome of this type of analysis can provide inputs for shaping integrated disease management programs for concurrent COPD and CVD conditions. 


\section{CHAPTER 6}

\section{CONCLUSION}

Despite considerable research interest in the potential risk of cardiac events associated with use of bronchodilators in COPD patients, few studies have analyzed the real-world prescribing rates of this highly utilized COPD therapy in cardiovascular disease. This study presents a unique national perspective to understand the effect of CVD on prescribing practices of bronchodilators in the United States.

Concurrent CVD diagnosis is a significant factor for reducing the probability of prescribing bronchodilators for COPD and the odds of prescribing were further decreased due to differences in gender, asthma and beta-blocker use. CVD patients who were female, not taking beta-blockers and not having concomitant asthma were 94\% less likely to be taking bronchodilators compared the non-CVD females with same characteristics. On the other hand, males not taking beta-blockers and not having concomitant asthma had 68\% lower probability when CVD coexisted with COPD. Female CVD patients taking beta-blockers and not living with asthma had only $20 \%$ chance of being a bronchodilator user than those without CVD. It is noteworthy that the general pattern observed in these national data is consistent with treatment guidelines that advise using bronchodilators with caution in the comorbid COPD-CVD patient population, however cardiovascular disease did not affect the utilization of bronchodilators in males taking beta-blockers. 
Our findings provide evidence that most patients with COPD and CVD are less likely to be prescribed bronchodilators, with the exception of males who were also prescribed beta-blockers. Thus this study highlights a specific patient subgroup for whom the guidelines are less likely to be observed. 


\title{
APPENDICES
}

\section{Appendix A: University of Rhode Island IRB Exemption Letter}

\author{
THE \\ UNIVERSITY \\ OF RHODE ISLAND \\ DNTSIOS OP KCSEARC: \\ AND ECONCBND \\ DEVIIOPAOAT \\ omet or neszeniow wTzanm

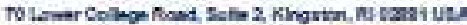

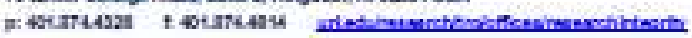 \\ THINK HIG GS WE DO' \\ FWA: $\quad 00003132$ \\ IRE: $\quad 00000599$ \\ DATE: APAl 6, 2015 \\ TO: Cyminla Willey, PhD \\ FROM: Untversity of Rhode Isiand IRE \\ STUDY TITLE: A cross-sectlona analysis of oronchodlator utilization in COPD and \\ cardlovascular comortidty \\ 736637-1 \\ LOCAL REFERENCE \% HU1415-137 \\ SUEMISSION TYPE: New Project \\ ACTION. DETERMINATION OF NOT HUMAN SUEUECT RESEARCH \\ EFFECTIVE DATE: APII 6, 2015 \\ Thank you for your submission of New Project materials for this research study. The Unlversity of Rhode \\ Island IFB has determined this project does not meet the definition of human subject research under the \\ purvew of federal regulation 45 CFR 46 regarding human subject research at this time. Therefore, your \\ project does not require institutional Revlew Bocrd (IRB) owersight. Amy changes in focus of als project \\ wil require futher review of the IFB. \\ If you have any questions, please contact us by emal at researchintegrnyapdsuntedu. Please include \\ your study title and reference rumber in al correspondence wth ris once. \\ findx-A thane \\ Andrea Rusnock, Ph. D \\ IRE Char
}


Table 1: Selected Information on the 2010 NAMCS Data and Analytic Sample

\begin{tabular}{|l|c|c|}
\hline Survey Item & Data & Result \\
\hline $\begin{array}{l}\text { Unweighted number of office visits recorded by participating } \\
\text { physicians }\end{array}$ & $\begin{array}{c}2010 \\
\text { NAMCS }\end{array}$ & 31,229 \\
\cline { 1 - 1 } $\begin{array}{l}\text { Weighted number of representative ambulatory-based medical } \\
\text { care office visits in the United States }\end{array}$ & $1,008,802,005$ \\
\cline { 1 - 1 } $\begin{array}{l}\text { Unweighted number of office visit records for COPD patients } \\
40 \text { years and over, without missing/unknown values }\end{array}$ & \multirow{2}{*}{$\begin{array}{c}\text { Analytic } \\
\text { sample }\end{array}$} & 263 \\
\cline { 1 - 1 } $\begin{array}{l}\text { Weighted number of representative COPD office visits for } \\
\text { patients } 40+\text { years in the United States }\end{array}$ & $11,627,061$ \\
\hline
\end{tabular}


Table 2: ICD-9-CM diagnosis codes for COPD and cardiovascular diseases

\begin{tabular}{|lcc|}
\hline Description of Diagnosis & $\begin{array}{c}\text { Diagnosis } \\
\text { code }\end{array}$ & $\begin{array}{c}\text { Study } \\
\text { variable }\end{array}$ \\
\hline Chronic bronchitis & $491 . x x$ & COPD \\
\hline Emphysema & $492 . x x$ & COPD \\
\hline Chronic airway obstruction & $496 . x x$ & COPD \\
\hline Acute myocardial infarction & $410 . x x$ & CVD \\
\hline Angina pectoris & $413 . x x$ & CVD \\
\hline Coronary artery disease & $414 . x x$ & CVD \\
\hline $\begin{array}{l}\text { Cardiac arrhythmias (including tachycardia, atrial } \\
\text { fibrillation) }\end{array}$ & $427 . x x$ & CVD \\
\hline Congestive heart failure & $428 . x x$ & CVD \\
\hline
\end{tabular}


Table 3: List of NAMCS 2010 Pharmacologic classes and codes of bronchodilator medications

\begin{tabular}{|c|c|c|c|c|}
\hline $\begin{array}{l}\text { Drug } \\
\text { therapeutic } \\
\text { category } \\
\text { Level } 2\end{array}$ & $\begin{array}{l}\text { Drug } \\
\text { therapeutic } \\
\text { category } \\
\text { Level } 3\end{array}$ & Sub-class & $\begin{array}{l}\text { Generic } \\
\text { names }\end{array}$ & $\begin{array}{l}\text { Brand } \\
\text { names } \\
\text { available in } \\
2010\end{array}$ \\
\hline \multirow{7}{*}{$\begin{array}{l}\text { Bronchodilators } \\
\text { (code 125) }\end{array}$} & \multirow{2}{*}{$\begin{array}{l}\text { Beta-2-agonists } \\
\text { (code } 180)\end{array}$} & $\begin{array}{l}\text { Short-acting } \\
\text { Beta-2-agonists } \\
\text { (SABA) }\end{array}$ & $\begin{array}{l}\text { Albuterol, } \\
\text { levalbuterol, } \\
\text { metaprotenerol }\end{array}$ & $\begin{array}{l}\text { Ventolin, } \\
\text { Proair, } \\
\text { Proventil, } \\
\text { VoSpire, } \\
\text { Xopenex, } \\
\end{array}$ \\
\hline & & $\begin{array}{l}\text { Long-acting } \\
\text { Beta-2-agonists } \\
\text { (LABA) }\end{array}$ & $\begin{array}{l}\text { Arformoterol, } \\
\text { formoterol, } \\
\text { salmeterol, }\end{array}$ & $\begin{array}{l}\text { Brovana, } \\
\text { Foradil, } \\
\text { Perforomist, } \\
\text { Serevent, }\end{array}$ \\
\hline & \multirow{2}{*}{$\begin{array}{l}\text { Anticholinergics } \\
\text { (code 299) }\end{array}$} & $\begin{array}{l}\text { Short-acting } \\
\text { Anticholinergics }\end{array}$ & Ipratropium & Atrovent \\
\hline & & $\begin{array}{l}\text { Long-acting } \\
\text { Anticholinergics }\end{array}$ & $\begin{array}{l}\text { Aclidinium, } \\
\text { tiotropium }\end{array}$ & $\begin{array}{l}\text { Tudorza } \\
\text { Pressair, } \\
\text { Spiriva }\end{array}$ \\
\hline & $\begin{array}{l}\text { Methylxanthines } \\
\text { (code 126) }\end{array}$ & Methylxanthines & $\begin{array}{l}\text { Aminophylline } \\
\text {, dyphylline, } \\
\text { theophylline }\end{array}$ & $\begin{array}{l}\text { Lufyllin, } \\
\text { Jay-Phyl, } \\
\text { Theo-24, } \\
\text { Elixophyllin, } \\
\text { Uniphyl, }\end{array}$ \\
\hline & \multirow{2}{*}{$\begin{array}{l}\text { Combination } \\
\text { bronchodilators } \\
\text { (code } 181)\end{array}$} & $\begin{array}{l}\text { Beta-2-agonists } \\
\text { plus } \\
\text { anticholinergic }\end{array}$ & $\begin{array}{l}\text { Albuterol/iprat } \\
\text { ropium, }\end{array}$ & Combivent, \\
\hline & & $\begin{array}{l}\text { Beta-2-agonists } \\
\text { plus } \\
\text { corticosteroid }\end{array}$ & $\begin{array}{l}\text { Salmeterol/Flut } \\
\text { icasone }\end{array}$ & Advair \\
\hline
\end{tabular}


Table 4: Demographic and Clinical characteristics of COPD visits $(\mathrm{N}=11,627,061)$

\begin{tabular}{|c|c|c|c|}
\hline \multirow{2}{*}{\multicolumn{2}{|c|}{ Characteristic }} & \multicolumn{2}{|c|}{ Weighted Estimates ${ }^{+}$} \\
\hline & & \multirow{2}{*}{$\begin{array}{c}\text { No. ('000s) } \\
69.2(0.9)\end{array}$} & \multirow[t]{2}{*}{$\%$} \\
\hline Age & Mean age * & & \\
\hline & $40-54$ & 1331 & 11.4 \\
\hline & $55-74$ & 6296 & 54.1 \\
\hline & $\geq 75$ & 4000 & 34.4 \\
\hline \multirow[t]{2}{*}{ Gender } & Female & 4999 & 43.0 \\
\hline & Male & 6628 & 57.0 \\
\hline \multirow[t]{4}{*}{ Race/ethnicity } & Non-Hispanic White & 9545 & 82.1 \\
\hline & Non-Hispanic Black & 1376 & 11.8 \\
\hline & Hispanic & 418 & 3.6 \\
\hline & Non-Hispanic Other & 289 & 2.5 \\
\hline \multirow[t]{4}{*}{ Region } & Northeast & 1556 & 13.4 \\
\hline & Midwest & 1928 & 16.6 \\
\hline & South & 6097 & 52.4 \\
\hline & West & 2046 & 17.6 \\
\hline \multirow[t]{2}{*}{ Tobacco Use } & Current & 7392 & 63.6 \\
\hline & Not current & 4235 & 36.4 \\
\hline \multirow[t]{2}{*}{ Cardiovascular disease CVD** } & Yes & 960 & 8.3 \\
\hline & No & 10667 & 91.7 \\
\hline \multirow[t]{2}{*}{ Bronchodilator prescription } & Yes & 6456 & 55.5 \\
\hline & No & 5171 & 44.5 \\
\hline \multirow{4}{*}{$\begin{array}{l}\text { Type of Bronchodilator } \\
\text { prescribed }\end{array}$} & Beta-2- agonist & 3638 & 56.4 \\
\hline & Anticholinergics & 1604 & 24.8 \\
\hline & Methylxanthines & 89 & 1.4 \\
\hline & Combination bronchodilators & 1126 & 17.4 \\
\hline \multirow[t]{2}{*}{ Concomitant Asthma } & Yes & 1677 & 14.4 \\
\hline & No & 9950 & 85.6 \\
\hline \multirow[t]{2}{*}{ Inhaled corticosteroid use } & Yes & 379 & 3.3 \\
\hline & No & 11248 & 96.7 \\
\hline \multirow[t]{2}{*}{ Antiarrhythmic drugs } & Yes & 1658 & 14.3 \\
\hline & No & 9969 & 85.7 \\
\hline \multirow[t]{2}{*}{ Beta-blockers } & Yes & 2726 & 23.4 \\
\hline & No & 8901 & 76.6 \\
\hline \multirow[t]{4}{*}{ Payment Source } & Private Insurance & 2996 & 25.8 \\
\hline & Medicare & 7848 & 67.5 \\
\hline & Medicaid & 505 & 4.3 \\
\hline & Other & 277 & 2.4 \\
\hline \multirow[t]{4}{*}{ Physician specialty } & General/Family Practice & 3424 & 29.4 \\
\hline & Internal Medicine & 2620 & 22.5 \\
\hline & Cardiology & 489 & 4.2 \\
\hline & Other specialty & 5094 & 44 \\
\hline \multicolumn{4}{|c|}{$\begin{array}{l}\text { * } \text { Mean age and standard error in years } \\
* * \text { CVD includes myocardial infarction }(0.05 \%) \text {, angina }(0.3 \%) \text {, coronary artery disease }(5.15 \%) \text {, cardiac } \\
\text { arrhythmias } 2.0 \% \text { (including tachycardia, atrial fibrillation), congestive heart failure }(0.7 \%) \\
+ \text { Weighted values represent the sample adjusted to represent national visit characteristics }\end{array}$} \\
\hline
\end{tabular}


Table 5: Utilization of bronchodilator by CVD status

\begin{tabular}{|l|c|c|c|}
\hline $\begin{array}{l}\text { Type of } \\
\text { bronchodilator (Yes) }\end{array}$ & $\begin{array}{c}\text { \% } \\
\text { CVD }\end{array}$ & $\begin{array}{c}\text { \% } \\
\text { No CVD }\end{array}$ & \multirow{2}{*}{ p-value } \\
\hline Beta-2-agonist & 5.1 & 94.9 & \multirow{2}{*}{$<0.0001$} \\
\cline { 1 - 2 } & 6.9 & 93.1 & \\
\hline Methylxanthines & 0 & 100 & \\
\hline $\begin{array}{l}\text { Combination } \\
\text { bronchodilators }\end{array}$ & 1.1 & 98.9 & \\
\hline
\end{tabular}


Table 6: Univariate Logistic Regression Analysis of NAMCS 2010 COPD visits of patients $\geq 40$ years with bronchodilator prescription by covariates

\begin{tabular}{|c|c|c|c|c|}
\hline Characteristic & & $\begin{array}{l}\% \text { of COPD } \\
\text { visits receiving } \\
\text { Bronchodilator } \\
\text { prescription }\end{array}$ & $\begin{array}{l}\text { Unadjusted } \\
\text { Odds Ratio } \\
(95 \% \mathrm{Cl})\end{array}$ & \\
\hline \multirow[t]{2}{*}{ Cardiovascular disease } & Yes & 32.3 & $0.35(0.31,0.4)$ & $<0.0001$ \\
\hline & No & 57.6 & 1.00 (reference) & \\
\hline \multirow[t]{2}{*}{ Gender } & Female & 46.1 & $0.51(0.47,0.55)$ & $<0.0001$ \\
\hline & Male & 62.7 & 1.00 (reference) & \\
\hline Age & & 55.5 & $1.01(1.01,1.02)$ & \\
\hline \multirow[t]{4}{*}{ Race/ethnicity } & Non-Hispanic White & 59.9 & 1.00 (reference) & $<0.0001$ \\
\hline & Non-Hispanic Black & 25.1 & $0.22(0.2,0.26)$ & \\
\hline & Hispanic & 53.1 & $0.76(0.62,0.92)$ & \\
\hline & Non-Hispanic Other & 58.4 & $0.94(0.74,1.19)$ & \\
\hline \multirow[t]{2}{*}{ Tobacco Use } & Current & 46.1 & $0.55(0.51,0.59)$ & $<0.0001$ \\
\hline & Not current & 60.9 & 1.00 (reference) & \\
\hline \multirow[t]{2}{*}{ Patients with Asthma } & Yes & 82.8 & $4.64(4.07,5.3)$ & $<0.0001$ \\
\hline & No & 50.9 & 1.00 (reference) & \\
\hline \multirow[t]{2}{*}{ Inhaled corticosteroid use } & Yes & 77.5 & $2.84(2.23,3.63)$ & $<0.0001$ \\
\hline & No & 54.8 & 1.00 (reference) & \\
\hline \multirow[t]{2}{*}{ Antiarrhythmic drugs } & Yes & 55.9 & $1.02(0.92,1.13)$ & 0.7159 \\
\hline & No & 55.5 & 1.00 (reference) & \\
\hline \multirow[t]{2}{*}{ Beta blockers } & Yes & 53.0 & $0.88(0.8,0.95)$ & 0.0023 \\
\hline & No & 56.3 & 1.00 (reference) & \\
\hline \multirow[t]{4}{*}{ Health Insurance type } & Private Insurance & 57.6 & $1.12(1.02,1.21)$ & \\
\hline & Medicare & 55.0 & 1.00 (reference) & 0.0005 \\
\hline & Medicaid & 57.1 & $1.09(0.91,1.31)$ & \\
\hline & Other & 45.6 & $0.69(0.54,0.88)$ & \\
\hline \multirow[t]{4}{*}{ Physician specialty } & $\begin{array}{l}\text { General/Family } \\
\text { Practice }\end{array}$ & 48.8 & 1.00 (reference) & $<0.0001$ \\
\hline & Internal Medicine & 42.1 & $0.76(0.69,0.85)$ & \\
\hline & Cardiology & 55.6 & $1.32(1.09,1.59)$ & \\
\hline & Other specialty & 67.0 & $2.13(1.95,2.33)$ & \\
\hline
\end{tabular}


Table 7: Modification of the effect of cardiovascular disease comorbidity on bronchodilator prescription in COPD

\begin{tabular}{|c|c|c|c|c|}
\hline $\begin{array}{l}\text { Exposure } \\
\text { (CVD) }\end{array}$ & Effect modifier (s) * & $\begin{array}{l}\text { Adjusted } \\
\text { Odds } \\
\text { Ratio }\end{array}$ & $\begin{array}{l}95 \% \\
\text { confidence } \\
\text { limits }\end{array}$ & $\begin{array}{l}\text { Effect measure } \\
\text { modification ** }\end{array}$ \\
\hline Yes & Male, no Asthma, no $\beta$-blocker & 0.32 & $0.25-0.40$ & $68 \%$ \\
\hline No & Male, no Asthma, no $\beta$-blocker & 1.00 & reference & \\
\hline Yes & Male, Asthma, no $\beta$-blocker & 0.17 & $0.10-0.31$ & $83 \%$ \\
\hline No & Male, Asthma, no $\beta$-blocker & 1.00 & reference & \\
\hline Yes & Male, no Asthma, $\beta$-blocker & 1.11 & $0.82-1.51$ & None \\
\hline No & Male, no Asthma, $\beta$-blocker & 1.00 & reference & \\
\hline Yes & Male, Asthma, $\beta$-blocker & 0.62 & $0.33-1.16$ & None \\
\hline No & Male, Asthma, $\beta$-blocker & 1.00 & reference & \\
\hline Yes & Female, no Asthma, no $\beta$-blocker & 0.06 & $0.04-0.09$ & $94 \%$ \\
\hline No & Female, no Asthma, no $\beta$-blocker & 1.00 & reference & \\
\hline Yes & Female, Asthma, no $\beta$-blocker & 0.03 & $0.02-0.06$ & $97 \%$ \\
\hline No & Female, Asthma, no $\beta$-blocker & 1.00 & reference & \\
\hline Yes & Female, no Asthma, $\beta$-blocker & 0.21 & $0.14-0.30$ & $79 \%$ \\
\hline No & Female, no Asthma, $\beta$-blocker & 1.00 & reference & \\
\hline Yes & Female, Asthma, $\beta$-blocker & 0.11 & $0.07-0.19$ & $89 \%$ \\
\hline No & Female, Asthma, $\beta$-blocker & 1.00 & reference & \\
\hline \multicolumn{5}{|c|}{$\begin{array}{l}\text { * Effect modifiers are gender, asthma and } \beta \text {-blockers } \\
\text { ** Effect measure modification was calculated by the difference between the odds in the CVD } \\
\text { group and the non-CVD comparison group, on a percent-scale }\end{array}$} \\
\hline
\end{tabular}


Table 8: Multivariate Logistic Regression Analysis of bronchodilator prescription in COPD without effect modification

\begin{tabular}{|c|c|c|}
\hline Characteristic & Factor & $\begin{array}{c}\text { Adjusted Odds Ratio } \\
(95 \% \text { CI })\end{array}$ \\
\hline \multicolumn{3}{|l|}{ Main effects } \\
\hline \multirow[t]{2}{*}{ CVD } & Yes & $0.30(0.25-0.35)$ \\
\hline & No & 1.00 (reference) \\
\hline \multirow[t]{2}{*}{ Gender } & Female & $0.50(0.46-0.55)$ \\
\hline & Male & 1.00 (reference) \\
\hline \multirow{2}{*}{ Beta blockers } & Yes & $0.90(0.82-1.00)$ \\
\hline & No & 1.00 (reference) \\
\hline \multirow[t]{2}{*}{ Asthma } & Yes & $4.85(4.17-5.63)$ \\
\hline & No & 1.00 (reference) \\
\hline \multirow[t]{4}{*}{ Race/ethnicity } & Non-Hispanic White & 1.00 (reference) \\
\hline & Non-Hispanic Black & $0.24(0.21-0.28)$ \\
\hline & Hispanic & $0.39(0.32-0.49)$ \\
\hline & Non-Hispanic Other & $1.49(1.15-1.93)$ \\
\hline \multirow[t]{2}{*}{ Tobacco Use } & Current & $0.55(0.50-0.61)$ \\
\hline & Not current & 1.00 (reference) \\
\hline \multirow[t]{2}{*}{ Inhaled corticosteroid use } & Yes & $1.52(1.15-2.00)$ \\
\hline & No & 1.00 (reference) \\
\hline \multirow[t]{2}{*}{ Antiarrhythmic drugs } & Yes & $1.71(1.50-1.94)$ \\
\hline & No & 1.00 (reference) \\
\hline \multirow[t]{4}{*}{ Health Insurance type } & Private Insurance & $1.47(1.32-1.62)$ \\
\hline & Medicare & 1.00 (reference) \\
\hline & Medicaid & $1.68(1.34-2.10)$ \\
\hline & Other & $1.15(0.85-1.55)$ \\
\hline \multirow[t]{4}{*}{ Physician specialty } & General/Family Practice & 1.00 (reference) \\
\hline & Internal Medicine & $0.72(0.64-0.81)$ \\
\hline & Cardiology & $1.94(1.56-2.43)$ \\
\hline & Other specialty & $2.00(1.81-2.22)$ \\
\hline
\end{tabular}


Figure 1: Flow Chart of application of study eligibility criteria

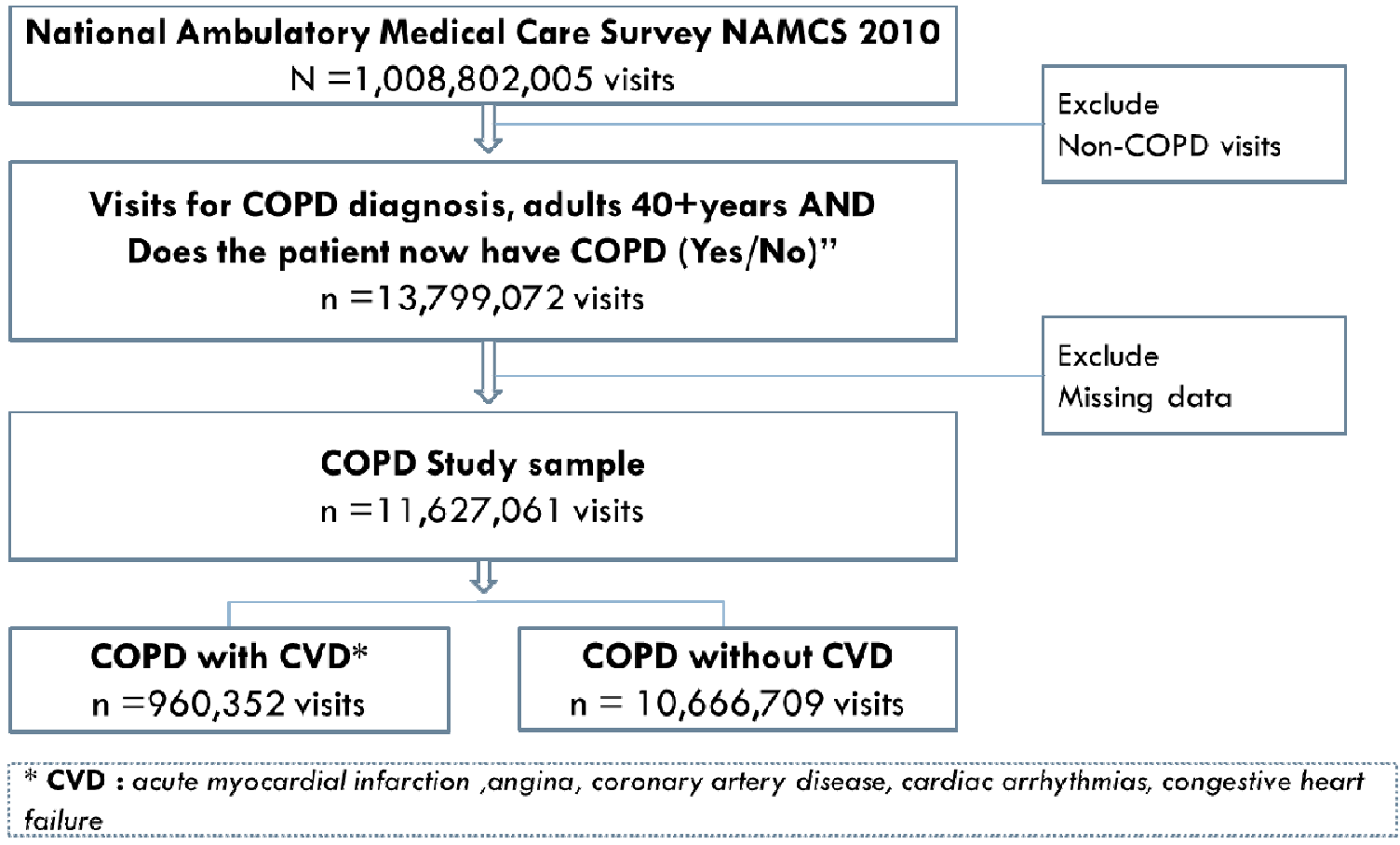


Figure 2: Two-way contingency table for Primary IV and DV

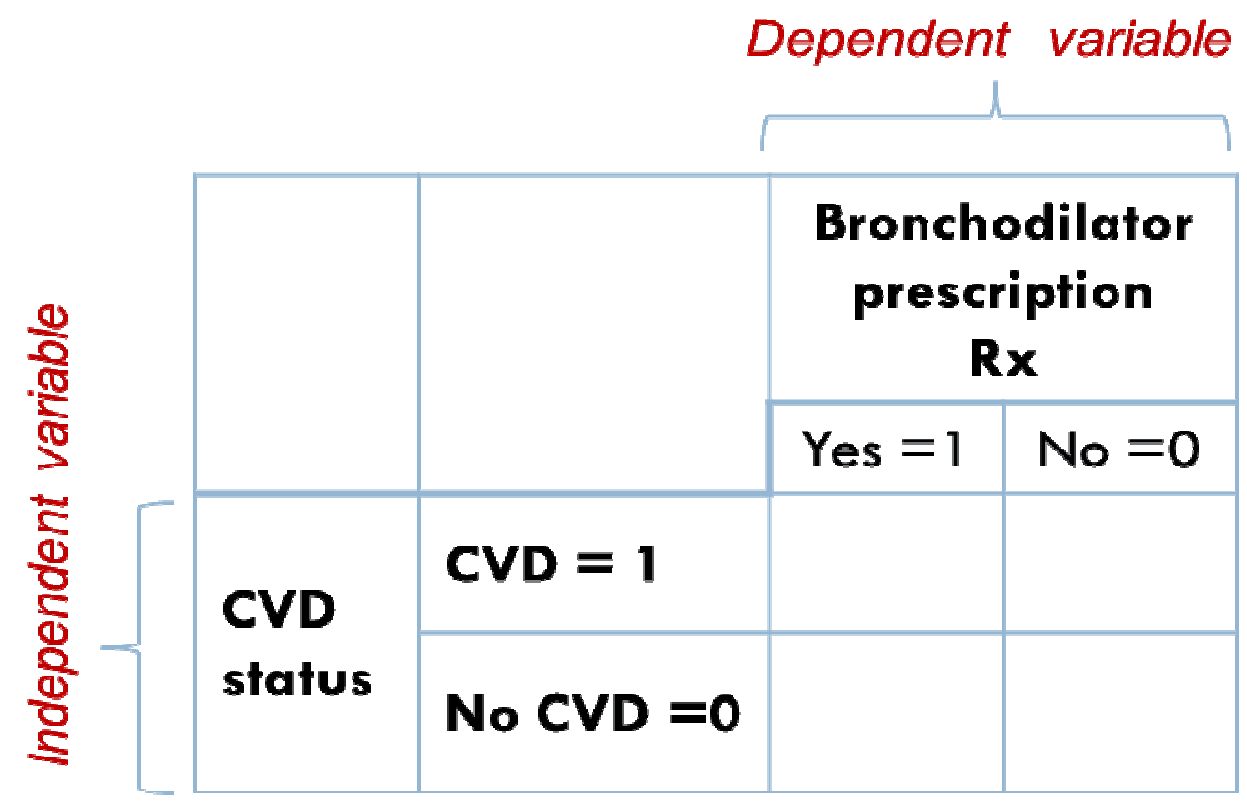


Figure 3: Parametric Assessment of Continuous Variables

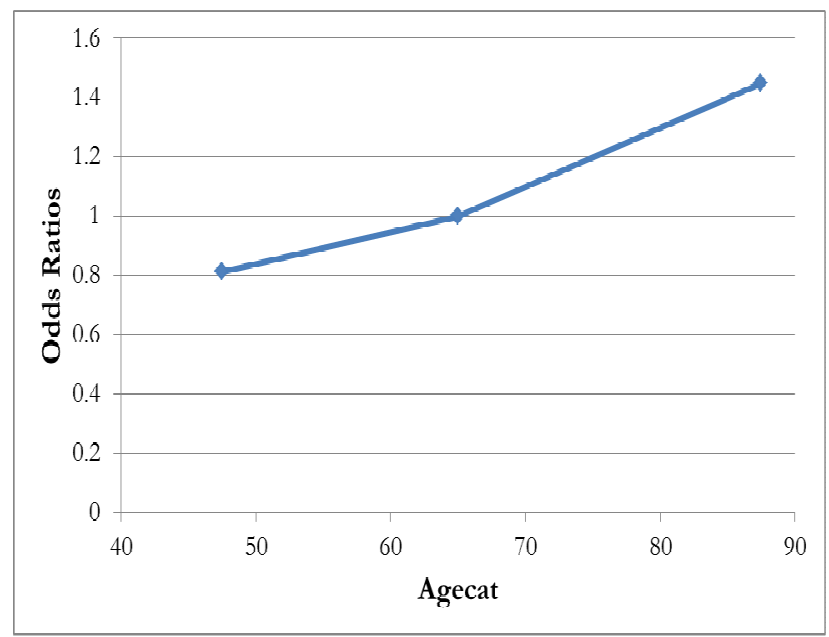

Reference class $=$ agecat 2

\begin{tabular}{|l|c|c|c|c|}
\hline Effect & $\begin{array}{c}\text { Age } \\
\text { category }\end{array}$ & Mid-point & \% Frequency & Odds Ratio \\
\hline agecat 1 & $40-54$ & 47.5 & 11.4 & 0.709 \\
\hline agecat 2 & $55-74$ & 65 & 54.1 & 1.00 \\
\hline agecat 3 & 75 \& over & 89.5 & 34.4 & 1.378 \\
\hline
\end{tabular}




\section{LIST OF REFERENCES}

1. Global Initiative for Chronic Obstructive Lung Disease (GOLD). Global Strategy for the Diagnosis, Management and Prevention of COPD. 2014; Available from: http://www.goldcopd.org/. Accessed November 20, 2014.

2. Ford ES, Croft JB, Mannino DM, Wheaton AG, Zhang X, Giles WH. COPD surveillance-United States, 1999-2011. Chest. 2013;144(1):284-305.

3. Vos T, Flaxman AD, Naghavi M, et al. Years lived with disability (YLDs) for 1160 sequelae of 289 diseases and injuries 1990-2010: a systematic analysis for the Global Burden of Disease Study 2010. The Lancet. 2012;380(9859):2163-2196.

4. World Health Organization. Global surveillance, Prevention and Control of Chronic Respiratory Diseases: A Comprehensive Approach. 2007; Available from: http://whqlibdoc.who.int/publications/2007/9789241563468 eng.pdf. Accessed January 2, 2015.

5. Lopez AD, Shibuya K, Rao C, et al. Chronic obstructive pulmonary disease: current burden and future projections. European Respiratory Journal. 2006;27(2):397-412.

6. Cazzola M, Matera MG. Bronchodilators: Current and Future. Clinics in Chest Medicine. 2014;35(1):191-201.

7. Hanania NA, Donohue JF. Pharmacologic Interventions in Chronic Obstructive Pulmonary Disease. Proceedings of the American Thoracic Society. 2007;4(7):526-534.

8. Macie C, Wooldrage K, Manfreda J, Anthonisen N. Cardiovascular morbidity and the use of inhaled bronchodilators. International Journal of Chronic Obstructive Pulmonary Disease. 2008;3(1):163.

9. Wilchesky M, Ernst P, Brophy JM, Platt RW, Suissa S. Bronchodilator use and the risk of arrhythmia in copd: Part 1: saskatchewan cohort study. Chest. 2012;142(2):298-304. 
10. Wilchesky M, Ernst P, Brophy JM, Platt RW, Suissa S. Bronchodilator use and the risk of arrhythmia in copd: Part 2: reassessment in the larger quebec cohort. Chest. 2012;142(2):305-311.

11. Bermingham M, O'Callaghan E, Dawkins I, et al. Are beta2-agonists responsible for increased mortality in heart failure? European Journal of Heart Failure. 2011;13(8):885-891.

12. Verhamme KM, Afonso A, Romio S, Stricker BC, Brusselle GG, Sturkenboom MC. Use of tiotropium Respimat Soft Mist Inhaler versus HandiHaler and mortality in patients with COPD. European Respiratory Journal. 2013;42(3):606-615.

13. Singh S, Loke YK, Enright P, Furberg CD. Pro-arrhythmic and pro-ischaemic effects of inhaled anticholinergic medications. Thorax. 2013;68(1):114-116.

14. Mannino DM, Thorn D, Swensen A, Holguin F. Prevalence and outcomes of diabetes, hypertension and cardiovascular disease in COPD. European Respiratory Journal. 2008;32(4):962-969.

15. Baty F, Putora PM, Isenring B, Blum T, Brutsche M. Comorbidities and burden of COPD: a population based case-control study. PloS One. 2013;8(5):e63285.

16. Chatila WM, Thomashow BM, Minai OA, Criner GJ, Make BJ. Comorbidities in Chronic Obstructive Pulmonary Disease. Proceedings of the American Thoracic Society. 2008;5(4):549-555.

17. Salvi SS, Barnes PJ. Chronic obstructive pulmonary disease in non-smokers. Lancet. 2009;374(9691):733-743.

18. Bang KM. Chronic obstructive pulmonary disease in nonsmokers by occupation and exposure: a brief review. Current Opinion in Pulmonary Medicine. 2015;21(2):149-154.

19. Lamprecht B, McBurnie MA, Vollmer WM, et al. COPD in never smokers: results from the population-based burden of obstructive lung disease study. Chest. 2011;139(4):752-763. 
20. Barnes PJ, Celli BR. Systemic manifestations and comorbidities of COPD. European Respiratory Journal. 2009;33(5):1165-1185.

21. Cavailles A, Brinchault-Rabin G, Dixmier A, et al. Comorbidities of COPD. European Respiratory Review: An Official Journal of the European Respiratory Society. 2013;22(130):454-475.

22. Smith MC, Wrobel JP. Epidemiology and clinical impact of major comorbidities in patients with COPD. International Journal of Chronic Obstructive Pulmonary Disease. 2014;9:871-888.

23. Pumar MI, Gray CR, Walsh JR, Yang IA, Rolls TA, Ward DL. Anxiety and depression-Important psychological comorbidities of COPD. Journal of Thoracic Disease. 2014;6(11):1615-1631.

24. Schnell K, Weiss CO, Lee T, et al. The prevalence of clinically-relevant comorbid conditions in patients with physician-diagnosed COPD: a crosssectional study using data from NHANES 1999-2008. BMC Pulmonary Medicine. 2012;12(26):1471-2466.

25. Vanfleteren L, Spruit MA, Groenen M, et al. Clusters of Comorbidities Based on Validated Objective Measurements and Systemic Inflammation in Patients with Chronic Obstructive Pulmonary Disease. American Journal of Respiratory and Critical Care Medicine. 2013;187(7):728-735.

26. Noteboom B, Jenkins S, Maiorana A, Cecins N, Ng C, Hill K. Comorbidities and medication burden in patients with chronic obstructive pulmonary disease attending pulmonary rehabilitation. Journal of Cardiopulmonary Rehabilitation and Prevention. 2014;34(1):75-79.

27. Ng TP, Niti M, Tan WC, Cao Z, Ong KC, Eng P. Depressive symptoms and chronic obstructive pulmonary disease: effect on mortality, hospital readmission, symptom burden, functional status, and quality of life. Archives of Internal Medicine. 2007;167(1):60-67.

28. Burgel PR, Escamilla R, Perez T, et al. Impact of comorbidities on COPDspecific health-related quality of life. Respiratory Medicine. 2013;107(2):233241. 
29. Sin DD, Anthonisen NR, Soriano JB, Agusti AG. Mortality in COPD: role of comorbidities. European Respiratory Journal. 2006;28(6):1245-1257.

30. Divo M, Cote C, de Torres JP, et al. Comorbidities and risk of mortality in patients with chronic obstructive pulmonary disease. American Journal of Respiratory and Critical Care Medicine. 2012;186(2):155-161.

31. Falk JA, Kadiev S, Criner GJ, Scharf SM, Minai OA, Diaz P. Cardiac Disease in Chronic Obstructive Pulmonary Disease. Proceedings of the American Thoracic Society. 2008;5(4):543-548.

32. Bhatt SP, Dransfield MT. Chronic obstructive pulmonary disease and cardiovascular disease. Translational Research. 2013;162(4):237-251.

33. Güder G, Brenner S, Störk S, Hoes A, Rutten FH. Chronic obstructive pulmonary disease in heart failure: accurate diagnosis and treatment. European Journal of Heart Failure. 2014;16(12):1273-1282.

34. Feary JR, Rodrigues LC, Smith CJ, Hubbard RB, Gibson JE. Prevalence of major comorbidities in subjects with COPD and incidence of myocardial infarction and stroke: a comprehensive analysis using data from primary care. Thorax. 2010;65(11):956-962.

35. Curkendall SM, deLuise C, Jones JK, et al. Cardiovascular Disease in Patients with Chronic Obstructive Pulmonary Disease, Saskatchewan Canada: Cardiovascular Disease in COPD Patients. Annals of Epidemiology. 2006;16(1):63-70.

36. Dalal AA, Shah M, Lunacsek O, Hanania NA. Clinical and economic burden of patients diagnosed with COPD with comorbid cardiovascular disease. Respiratory Medicine. 2011;105(10):1516-1522.

37. Osthoff M, Jenkins C, Leuppi J. Chronic obstructive pulmonary disease--a treatable disease. Swiss Medical Weekly. 2013;143:w13777.

38. Ferguson GT, Funck-Brentano C, Fischer T, Darken P, Reisner C. Cardiovascular safety of salmeterol in COPD. Chest. 2003;123(6):1817-1824. 
39. Salpeter SR, Ormiston TM, Salpeter EE. Cardiovascular effects of betaagonists in patients with asthma and COPD: a meta-analysis. Chest. 2004;125(6):2309-2321.

40. Van Noord JA, Cornelissen PJ, Aumann JL, Platz J, Mueller A, Fogarty C. The efficacy of tiotropium administered via Respimat Soft Mist Inhaler or HandiHaler in COPD patients. Respiratory Medicine. 2009;103(1):22-29.

41. Groenwold RH, de Vries F, de Boer A, et al. Balance measures for propensity score methods: a clinical example on beta-agonist use and the risk of myocardial infarction. Pharmacoepidemiology and Drug Safety.

2011;20(11):1130-1137.

42. Suh DC, Lau H, Pokras SM, Choi IS, Valiyeva E. Sex differences in ambulatory visits for chronic obstructive pulmonary disease, based on the National Ambulatory Medical Care Survey and the National Hospital Ambulatory Medical Care Survey from 1995 to 2004. Respiratory Care. 2008;53(11):1461-1469.

43. National Center for Health Statistics. National Ambulatory Medical Care Survey. 2010; Available at http://www.cdc.gov/nchs/ahcd/ahcd_questionnaires.htm. Accessed February $12,2015$.

44. Ford ES, Mannino DM, Wheaton AG, et al. Trends in the use, sociodemographic correlates, and undertreatment of prescription medications for chronic obstructive pulmonary disease among adults with chronic obstructive pulmonary disease in the United States from 1999 to 2010. PloS One. 2014;9(4):e95305.

45. Drivenes E, Ostrem A, Melbye H. Predictors of ICS/LABA prescribing in COPD patients: a study from general practice. BMC Family Practice. 2014;15:42.

46. Hawkins NM, Petrie MC, MacDonald MR, et al. Heart Failure and Chronic Obstructive Pulmonary Disease: The Quandary of Beta-Blockers and BetaAgonists. Journal of the American College of Cardiology. 2011;57(21):21272138.

47. Chen J, Radford MJ, Wang Y, Marciniak TA, Krumholz HM. Effectiveness of beta-blocker therapy after acute myocardial infarction in elderly patients with 
chronic obstructive pulmonary disease or asthma. Journal of the American College of Cardiology. 2001;37(7):1950-1956.

48. Au DH, Curtis JR, Every NR, McDonell MB, Fihn SD. Association between inhaled beta-agonists and the risk of unstable angina and myocardial infarction. Chest. 2002;121(3):846-851.

49. Amabile CM, Spencer AP. Keeping your patient with heart failure safe: A review of potentially dangerous medications. Archives of Internal Medicine. 2004;164(7):709-720.

50. Souverein PC, Berard A, Van Staa TP, et al. Use of oral glucocorticoids and risk of cardiovascular and cerebrovascular disease in a population based casecontrol study. Heart. 2004;90(8):859-865. 


\section{BIBLIOGRAPHY}

Amabile, C. M. and A. P. Spencer. "Keeping Your Patient with Heart Failure Safe: A Review of Potentially Dangerous Medications." Archives of Internal Medicine 164, no. 7 (2004): 709-720.

Au, D. H., J. R. Curtis, N. R. Every, M. B. McDonell and S. D. Fihn. "Association between Inhaled Beta-Agonists and the Risk of Unstable Angina and Myocardial Infarction." Chest 121, no. 3 (2002): 846-51.

Bang, K. M. "Chronic Obstructive Pulmonary Disease in Nonsmokers by Occupation and Exposure: A Brief Review." Current Opinion in Pulmonary Medicine 21, no. 2 (2015): 149-54.

Barnes, P. J. and B. R. Celli. "Systemic Manifestations and Comorbidities of Copd." European Respiratory Journal 33, no. 5 (2009): 1165-85.

Baty, F., P. M. Putora, B. Isenring, T. Blum and M. Brutsche. "Comorbidities and Burden of Copd: A Population Based Case-Control Study." PloS One 8, no. 5 (2013): e63285.

Bermingham, M., E. O'Callaghan, I. Dawkins, S. Miwa, S. Samsudin, K. McDonald and M. Ledwidge. "Are Beta2-Agonists Responsible for Increased Mortality in Heart Failure?" European Journal of Heart Failure 13, no. 8 (2011): 885-91.

Bhatt, Surya P. and Mark T. Dransfield. "Chronic Obstructive Pulmonary Disease and Cardiovascular Disease." Translational Research 162, no. 4 (2013): 237-251.

Burgel, P. R., R. Escamilla, T. Perez, P. Carre, D. Caillaud, P. Chanez, C. Pinet, G. Jebrak, G. Brinchault, I. Court-Fortune, J. L. Paillasseur, N. Roche and Initiatives Bpco Scientific Committee. "Impact of Comorbidities on Copd- 
Specific Health-Related Quality of Life." Respiratory Medicine 107, no. 2 (2013): 233-41.

Cavailles, A., G. Brinchault-Rabin, A. Dixmier, F. Goupil, C. Gut-Gobert, S. Marchand-Adam, J. C. Meurice, H. Morel, C. Person-Tacnet, C. Leroyer and P. Diot. "Comorbidities of Copd." European Respiratory Review: An Official Journal of the European Respiratory Society 22, no. 130 (2013): 454-75.

Cazzola, Mario and Maria Gabriella Matera. "Bronchodilators: Current and Future." Clinics in Chest Medicine 35, no. 1 (2014): 191-201.

Chatila, Wissam M., Byron M. Thomashow, Omar A. Minai, Gerard J. Criner and Barry J. Make. "Comorbidities in Chronic Obstructive Pulmonary Disease." Proceedings of the American Thoracic Society 5, no. 4 (2008): 549-555.

Chen, J., M. J. Radford, Y. Wang, T. A. Marciniak and H. M. Krumholz. "Effectiveness of Beta-Blocker Therapy after Acute Myocardial Infarction in Elderly Patients with Chronic Obstructive Pulmonary Disease or Asthma." Journal of the American College of Cardiology 37, no. 7 (2001): 1950-6.

Curkendall, Suellen M., Cynthia deLuise, Judith K. Jones, Stephan Lanes, Mary Rose Stang, Earl Goehring Jr and Dewei She. "Cardiovascular Disease in Patients with Chronic Obstructive Pulmonary Disease, Saskatchewan Canada: Cardiovascular Disease in Copd Patients." Annals of Epidemiology 16, no. 1 (2006): 63-70.

Dalal, Anand A., Manan Shah, Orsolya Lunacsek and Nicola A. Hanania. "Clinical and Economic Burden of Patients Diagnosed with Copd with Comorbid Cardiovascular Disease." Respiratory Medicine 105, no. 10 (2011): 1516-1522.

Divo, M., C. Cote, J. P. de Torres, C. Casanova, J. M. Marin, V. Pinto-Plata, J. Zulueta, C. Cabrera, J. Zagaceta, G. Hunninghake, B. Celli and Bode Collaborative Group. "Comorbidities and Risk of Mortality in Patients with 
Chronic Obstructive Pulmonary Disease." American Journal of Respiratory and Critical Care Medicine 186, no. 2 (2012): 155-61.

Drivenes, E., A. Ostrem and H. Melbye. "Predictors of Ics/Laba Prescribing in Copd Patients: A Study from General Practice." BMC Family Practice 15, (2014): 42.

Falk, Jeremy A., Steven Kadiev, Gerard J. Criner, Steven M. Scharf, Omar A. Minai and Philip Diaz. "Cardiac Disease in Chronic Obstructive Pulmonary Disease." Proceedings of the American Thoracic Society 5, no. 4 (2008): 543-548.

Feary, J. R., L. C. Rodrigues, C. J. Smith, R. B. Hubbard and J. E. Gibson. "Prevalence of Major Comorbidities in Subjects with Copd and Incidence of Myocardial Infarction and Stroke: A Comprehensive Analysis Using Data from Primary Care." Thorax 65, no. 11 (2010): 956-62.

Ferguson, G. T., C. Funck-Brentano, T. Fischer, P. Darken and C. Reisner. "Cardiovascular Safety of Salmeterol in Copd." Chest 123, no. 6 (2003): 181724.

Ford, E. S., D. M. Mannino, A. G. Wheaton, L. Presley-Cantrell, Y. Liu, W. H. Giles and J. B. Croft. "Trends in the Use, Sociodemographic Correlates, and Undertreatment of Prescription Medications for Chronic Obstructive Pulmonary Disease among Adults with Chronic Obstructive Pulmonary Disease in the United States from 1999 to 2010." PloS One 9, no. 4 (2014): e95305.

Ford, Earl S., Janet B. Croft, David M. Mannino, Anne G. Wheaton, Xingyou Zhang and Wayne H. Giles. "Copd Surveillance-United States, 1999-2011." Chest 144, no. 1 (2013): 284-305.

Global Initiative for Chronic Obstructive Lung Disease (GOLD), "Global Strategy for the Diagnosis, Management and Prevention of Copd" Available from: http://www.goldcopd.org/ (accessed November 20 2014). 
Groenwold, R. H., F. de Vries, A. de Boer, W. R. Pestman, F. H. Rutten, A. W. Hoes and O. H. Klungel. "Balance Measures for Propensity Score Methods: A Clinical Example on Beta-Agonist Use and the Risk of Myocardial Infarction." Pharmacoepidemiology and Drug Safety 20, no. 11 (2011): 1130-7.

Güder, Gülmisal, Susanne Brenner, Stefan Störk, Arno Hoes and Frans H. Rutten. "Chronic Obstructive Pulmonary Disease in Heart Failure: Accurate Diagnosis and Treatment." European Journal of Heart Failure 16, no. 12 (2014): 12731282.

Hanania, Nicola A. and James F. Donohue. "Pharmacologic Interventions in Chronic Obstructive Pulmonary Disease." Proceedings of the American Thoracic Society 4, no. 7 (2007): 526-534.

Hawkins, Nathaniel M., Mark C. Petrie, Michael R. MacDonald, Pardeep S. Jhund, Leonardo M. Fabbri, John Wikstrand and John J. V. McMurray. "Heart Failure and Chronic Obstructive Pulmonary Disease: The Quandary of Beta-Blockers and Beta-Agonists." Journal of the American College of Cardiology 57, no. 21 (2011): 2127-2138.

Lamprecht, B., M. A. McBurnie, W. M. Vollmer, G. Gudmundsson, T. Welte, E. Nizankowska-Mogilnicka, M. Studnicka, E. Bateman, J. M. Anto, P. Burney, D. M. Mannino, S. A. Buist and Bold Collaborative Research Group. "Copd in Never Smokers: Results from the Population-Based Burden of Obstructive Lung Disease Study." Chest 139, no. 4 (2011): 752-63.

Lopez, A. D., K. Shibuya, C. Rao, C. D. Mathers, A. L. Hansell, L. S. Held, V. Schmid and S. Buist. "Chronic Obstructive Pulmonary Disease: Current Burden and Future Projections." European Respiratory Journal 27, no. 2 (2006): 397-412.

Macie, Christine, Kate Wooldrage, Jure Manfreda and Nicholas Anthonisen. "Cardiovascular Morbidity and the Use of Inhaled Bronchodilators." 
International Journal of Chronic Obstructive Pulmonary Disease 3, no. 1 (2008): 163.

Mannino, David M, D Thorn, A Swensen and F Holguin. "Prevalence and Outcomes of Diabetes, Hypertension and Cardiovascular Disease in Copd." European Respiratory Journal 32, no. 4 (2008): 962-969.

National Center for Health Statistics, "National Ambulatory Medical Care Survey" Available at http://www.cdc.gov/nchs/ahcd/ahcd questionnaires.htm (accessed February 12 2015).

Ng, T. P., M. Niti, W. C. Tan, Z. Cao, K. C. Ong and P. Eng. "Depressive Symptoms and Chronic Obstructive Pulmonary Disease: Effect on Mortality, Hospital Readmission, Symptom Burden, Functional Status, and Quality of Life." Archives of Internal Medicine 167, no. 1 (2007): 60-7.

Noteboom, B., S. Jenkins, A. Maiorana, N. Cecins, C. Ng and K. Hill. "Comorbidities and Medication Burden in Patients with Chronic Obstructive Pulmonary Disease Attending Pulmonary Rehabilitation." Journal of Cardiopulmonary Rehabilitation and Prevention 34, no. 1 (2014): 75-9.

Osthoff, M., C. Jenkins and J. Leuppi. "Chronic Obstructive Pulmonary Disease--a Treatable Disease." Swiss Medical Weekly 143, (2013): w13777.

Pumar, M. I., C. R. Gray, J. R. Walsh, I. A. Yang, T. A. Rolls and D. L. Ward. "Anxiety and Depression-Important Psychological Comorbidities of Copd." Journal of Thoracic Disease 6, no. 11 (2014): 1615-1631.

Salpeter, S. R., T. M. Ormiston and E. E. Salpeter. "Cardiovascular Effects of BetaAgonists in Patients with Asthma and Copd: A Meta-Analysis." Chest 125, no. 6 (2004): 2309-21. 
Salvi, S. S. and P. J. Barnes. "Chronic Obstructive Pulmonary Disease in NonSmokers." Lancet 374, no. 9691 (2009): 733-43.

Schnell, K., C. O. Weiss, T. Lee, J. A. Krishnan, B. Leff, J. L. Wolff and C. Boyd. "The Prevalence of Clinically-Relevant Comorbid Conditions in Patients with Physician-Diagnosed Copd: A Cross-Sectional Study Using Data from Nhanes 1999-2008." BMC Pulmonary Medicine 12, no. 26 (2012): 1471-2466.

Sin, D. D., N. R. Anthonisen, J. B. Soriano and A. G. Agusti. "Mortality in Copd: Role of Comorbidities." European Respiratory Journal 28, no. 6 (2006): 1245-1257.

Singh, Sonal, Yoon K Loke, Paul Enright and Curt D Furberg. "Pro-Arrhythmic and Pro-Ischaemic Effects of Inhaled Anticholinergic Medications." Thorax 68, no. 1 (2013): 114-116.

Smith, M. C. and J. P. Wrobel. "Epidemiology and Clinical Impact of Major Comorbidities in Patients with Copd." International Journal of Chronic Obstructive Pulmonary Disease 9, (2014): 871-88.

Souverein, P C, A Berard, T P Van Staa, C Cooper, A C G Egberts, H G M Leufkens and B R Walker. "Use of Oral Glucocorticoids and Risk of Cardiovascular and Cerebrovascular Disease in a Population Based Case-Control Study." Heart 90, no. 8 (2004): 859-865.

Suh, D. C., H. Lau, S. M. Pokras, I. S. Choi and E. Valiyeva. "Sex Differences in Ambulatory Visits for Chronic Obstructive Pulmonary Disease, Based on the National Ambulatory Medical Care Survey and the National Hospital Ambulatory Medical Care Survey from 1995 to 2004." Respiratory Care 53, no. 11 (2008): 1461-9.

Van Noord, J. A., P. J. Cornelissen, J. L. Aumann, J. Platz, A. Mueller and C. Fogarty. "The Efficacy of Tiotropium Administered Via Respimat Soft Mist Inhaler or Handihaler in Copd Patients." Respiratory Medicine 103, no. 1 (2009): 22-9. 
Vanfleteren, Legw, M. A. Spruit, M. Groenen, S. Gaffron, V. P. M. van Empel, P. L. B. Bruijnzeel, E. P. A. Rutten, J. O. t Roodt, E. F. M. Wouters and F. M. E. Franssen. "Clusters of Comorbidities Based on Validated Objective Measurements and Systemic Inflammation in Patients with Chronic Obstructive Pulmonary Disease." American Journal of Respiratory and Critical Care Medicine 187, no. 7 (2013): 728-735.

Verhamme, K. M., A. Afonso, S. Romio, B. C. Stricker, G. G. Brusselle and M. C. Sturkenboom. "Use of Tiotropium Respimat Soft Mist Inhaler Versus Handihaler and Mortality in Patients with Copd." European Respiratory Journal 42, no. 3 (2013): 606-15.

Vos, Theo, Abraham D. Flaxman, Mohsen Naghavi, Rafael Lozano, Catherine Michaud, Majid Ezzati. "Years Lived with Disability (Ylds) for 1160 Sequelae of 289 Diseases and Injuries 1990-2010: A Systematic Analysis for the Global Burden of Disease Study 2010." The Lancet 380, no. 9859 (2012): 2163-2196.

Wilchesky, Machelle, Pierre Ernst, James M. Brophy, Robert W. Platt and Samy Suissa. "Bronchodilator Use and the Risk of Arrhythmia in Copd: Part 1: Saskatchewan Cohort Study." Chest 142, no. 2 (2012): 298-304.

Wilchesky, Machelle, Pierre Ernst, James M. Brophy, Robert W. Platt and Samy Suissa. "Bronchodilator Use and the Risk of Arrhythmia in Copd: Part 2: Reassessment in the Larger Quebec Cohort." Chest 142, no. 2 (2012): 305-311.

World Health Organization, "Global Surveillance, Prevention and Control of Chronic Respiratory Diseases: A Comprehensive Approach" Available from: http://whqlibdoc.who.int/publications/2007/9789241563468 eng.pdf. (accessed January 2 2015). 